\title{
Electrophysiological Evidence for the Continuous Processing of Linguistic Categories of Regular and Irregular Verb Inflection in German
}

\author{
Eva Smolka', Patrick H. Khader ${ }^{2,3}$, Richard Wiese ${ }^{2}$, \\ Pienie Zwitserlood ${ }^{4}$, and Frank Rösler ${ }^{2,5}$
}

\begin{abstract}
A central question concerning word recognition is whether linguistic categories are processed in continuous or categorical ways, in particular, whether regular and irregular inflection is stored and processed by the same or by distinct systems. Here, we contribute to this issue by contrasting regular (regular stem, regular suffix) with semi-irregular (regular stem, irregular suffix) and irregular (irregular stem, irregular suffix) participle formation in a visual priming experiment on German verb inflection. We measured ERPs and RTs and manipulated the inflectional and meaning relatedness between primes and targets. Inflected verb targets (e.g., leite, "head") were preceded either by themselves, by their participle (geleitet, "headed"), by a semantically related verb in the same inflection as the target (fübre, "guide") or in the participle form (gefübrt, "guided"), or by an unrelated verb in the
\end{abstract}

\section{INTRODUCTION}

A central issue in the processing of word recognition is whether linguistic categories are processed in continuous or categorical ways. The distinction between regular and irregular inflection has often been used to study whether they are processed and stored in the same or in different systems. In English, regularly inflected words, such as walked, are easily segregable into the stem (walk), which encodes the semantic properties of the verb and the suffix (-ed) that entails the (syntactic) feature for past tense [+ past]. Irregularly inflected words, such as sung and brought, show no transparent distinction between stem and suffix. The first psycholinguistic evidence that English regular and irregular verbs are processed by two distinct systems was provided by Stanners, Neiser, Hernon, and Hall (1979). In a long-lag repetition-priming paradigm, they compared the influence of inflectional and derivational variations of a verb on its uninflected base form. Regular past tense forms primed the base as well as did identity primes. That is, poured primed pour

\footnotetext{
${ }^{1}$ University of Konstanz, ${ }^{2}$ Marburg University, ${ }^{3}$ Ludwig-Maximilians University of Munich, ${ }^{4}$ University of Münster, ${ }^{5}$ University of Potsdam
}

same inflection (nenne, "name"). Results showed that behavioral and ERP priming effects were gradually affected by verb regularity. Regular participles produced a widely distributed frontal and parietal effect, irregular participles produced a small left parietal effect, and semi-irregular participles yielded an effect in-between these two in terms of amplitude and topography. The behavioral and ERP effects further showed that the priming because of participles differs from that because of semantic associates for all verb types. These findings argue for a single processing system that generates participle priming effects for regular, semi-irregular, and irregular verb inflection. Together, the findings provide evidence that the linguistic categories of verb inflection are processed continuously. We present a single-system model that can adequately account for such graded effects.

to the same extent as pour primed pour. Irregular past tense forms also facilitated their base, such as bend priming bent or shook priming shake, but to a lesser extent than identical primes. Similar priming was observed for derivations-predictable primed predict and retention primed retain-but to a lesser extent than identical primes.

Stanners et al. (1979) drew a distinction between full and partial activation that a base may receive and inferred two different mechanisms. In the first system, only the base has a lexical entry, which is shared by all other regularly inflected forms. These are parsed into suffix and base before memory access, so that only the base is accessed. This produces full activation of the base when a regularly inflected form is encountered. The second system comprises lexical entries of whole words, both for irregularly inflected forms and derivations. Although these entries are stored separately, they are nevertheless tightly connected with their respective base, thus producing the partial activation of an irregular base when the past tense form is accessed.

Subsequent priming studies on English regular and irregular past tense forms were mostly interpreted to support the assumption of two distinct systems, in spite of more complex findings: Regularly inflected verbs 
induced full priming (Marslen-Wilson, 1999; Napps, 1989; Fowler, Napps, \& Feldman, 1985) as well as partial priming (Fowler et al., 1985) on their base forms, whereas irregular verbs induced full priming (Forster, Davis, Schoknecht, \& Carter, 1987), partial priming (Napps, 1989), or no priming at all (Marslen-Wilson, 1999).

In spite of diverging evidence, the findings proposing a dissociation between regular and irregular inflection have generally drawn more attention than those showing similarities. Contrastive data on regular and irregular inflection are in line with Chomsky's (1970) lexicalist hypothesis, which distinguishes between universal and language-specific (phrase structure and transformational) rules and information in the lexicon. The psycholinguistic implementation of this hypothesis takes the form of socalled "dual-mechanism" models, assuming two innately distinct systems, each incorporating a specific processing style: The default system parses regular forms into their constituent morphemes, whereas the memory system stores and retrieves all exceptions to the default as undecomposed whole words. A major assumption of dualmechanism models is that regular and irregular verbs are processed by these two independent systems. Hence, the different processing characteristics of the two systems should be reflected in different performance patterns between regular and irregular verbs (e.g., Pinker \& Ullman, 2002; Clahsen, 1999; Pinker, 1998; Prasada \& Pinker, 1993). That is, the linguistic categories of regular and irregular verbs are assumed to be processed by categorically distinct systems. Importantly, in these models, membership of one of the systems is an all-or-none matter. Hence, regularly inflected forms (e.g., brings or bringing) of verbs with additional irregularly inflected forms, such as brought, must necessarily be handled by the same storage system.

\section{Neural Correlates of Processing of Regular and Irregular Verbs}

So far, neural correlates of morphological differences between regular and irregular verbs come from data from aphasic patients (e.g., Marslen-Wilson \& Tyler, 1998, 2007; Ullman et al., 1997, 2005) and from brain-imaging studies (for a review, see Lavric, Pizzagalli, Forstmeier, \& Rippon, 2001) using positron-emission tomography (e.g., Jaeger et al., 1996; for contrary findings, see Sach, Seitz, \& Indefrey, 2004) or fMRI (e.g., Beretta et al., 2003; for a contrary view, see Seidenberg \& Arnoldussen, 2003). For example, Ullman and colleagues (Ullman et al., 1997, 2005) postulated two (dual) mechanisms that are implemented in distinct neural systems, that is, the default system corresponds to a procedural-memory system in left-frontal structures (including Broca's area and left $\mathrm{BG}$ ) involved in the parsing of regular inflection, whereas the lexical storage of irregular word forms is part of a declarative-memory system in left temporal/temporoparietal structures. Another dual-system/dual-process type of model, developed by Marslen-Wilson and Tyler (1998, 2007), argues that a specific left-hemispheric neural system supports processes of regular inflectional morphology, whereas whole-form and stem-based access processes have a broader bihemispheric substrate.

Whereas patient and fMRI studies provide functional and spatial dissociations between regular and irregular verbs, ERPs provide functional dissociations with high temporal resolution. Furthermore, certain ERP components are associated with certain linguistic processes, so that the components may be used as indicators for particular processes. The dual-mechanism model of Ullman and colleagues assumes that regular forms are parsed in frontal areas, whereas irregular forms are retrieved from declarative memory in parietal areas. Mapping the parsing and retrieval processes onto ERP components, parsing processes of regular inflections should be reflected in left anterior negativities (LAN; e.g., Krott, Baayen, \& Hagoort, 2006), whereas the retrieval of irregular forms should be reflected in centro-parietal negativities that peak around 400 msec after target onset (N400; e.g., Bentin, McCarthy, \& Wood, 1985; for a recent overview of language-related ERP components, see Kutas \& Federmeier, 2007). We will briefly review the ERP data on verb inflection, which were mainly derived from two paradigms, grammatical violations and repetition priming. Because these paradigms involve different processes and are thus difficult to compare, the data can be regarded as two separate sources of evidence for the putative cognitive mechanisms underlying the processing of regular and irregular verb inflection.

Grammatical violations of regular and irregular verbs in English have been created by inserting either incorrect past tense forms in sentence contexts that require the future tense, such as The man will work/*worked on the platform versus The man will stand/*stood on the platform (Allen, Badecker, \& Osterhout, 2003), or uninflected verbs in sentence contexts that required past tense forms, such as Yesterday I frowned/*frown at Bill versus Yesterday I ground/*grind up coffee (Newman, Ullman, Pancheva, Waligura, \& Neville, 2007). Other studies used a different type of grammatical violation by embedding incorrect combinations of stems and suffixes in sentences. In particular, the regular suffix or stem vowel (or "default" in dual-mechanism terms) was applied to irregular verbs (e.g., English brought vs. *bringed) or an irregular suffix or stem vowel was applied to regular verbs (e.g., English warned vs. *sept; see Morris \& Holcomb, 2005; note that this study used different regular verbs in the comparison of correct vs. violated). In German, Penke et al. (1997) exchanged the participle suffixes and affixed the regular suffix $-t$ to irregular participles, creating violated forms like *aufgeladet (as compared with the correct form aufgeladen, "loaded on"), ${ }^{1}$ and the irregular suffix -en to regular participles, as in *durchgetanzen (as compared with the correct form durchgetanzt, "danced through"). Applying the same violation paradigm as in German, further studies in Italian (Gross, Say, Kleingers, Clahsen, \& 
Münte, 1998) and Catalan (Rodriguez-Fornells, Clahsen, Lleo, Zaake, \& Münte, 2001) contrasted more than two verb regularities by comparing correct participle forms with incorrect stem-and-suffix combinations.

The top of Table 1 summarizes the characteristics of the studies using violation paradigms. Interestingly, they show that the most distinct effects surfaced, ranging from null effects to LAN, other left (not anterior) negativities, right anterior negativities, N400, and late positivities (P600) for both regular and irregular inflection. Although these heterogeneous effects do not unequivocally indicate categorical processing differences between regular and irregular verbs, they were mostly discussed as if they provided evidence for a binary distinction between regular and irregular verb inflection.

In contrast to studies using violation paradigms, in which the critical participles are embedded in sentences, repetition-priming studies present single words. The bottom of Table 1 summarizes all studies applying repetition priming to contrast regular and irregular verb inflection. The repetition of a written word within a list has been found to reduce the N400 amplitude on the second presentation relative to the first presentation. This effect has been interpreted to represent, similar to behavioral priming, the facilitated lexical access of a word relative to its unprimed presentation (e.g., Bentin \& Peled, 1990; Rugg, 1990). Using this logic in a long-lag priming design, Weyerts, Münte, Smid, and Heinze (1996) were the first to investigate verb inflection by means of ERPs. Relative to the first (unprimed) presentation, German regular participles (e.g., getanzt, "danced") showed a reduction in the N400 and post-N400 range when they were preceded by themselves (identity condition) or by their infinitive (e.g., tanzen, "dance"). Irregular participles (e.g., geboten, "bid") also showed N400 reductions when preceded by themselves or by their infinitive (e.g., bieten, "bid"), although some 100 msec later than regular participles. Differences between regular and irregular verb inflection thus mainly showed in the latencies of the N400. Whereas the patterns of identity and infinitive priming were similar for regular verbs (which was interpreted to indicate full priming for regular verb inflection), irregular infinitive priming had a later onset and a more positive amplitude than irregular identity priming (which was interpreted to indicate partial priming for irregular verbs).

For English, Münte, Say, Clahsen, Schiltz, and Kutas (1999) used repetition priming without an identity condition but with an unrelated baseline (e.g., walked-stretch) instead. Relative to this baseline, regular verb stems preceded by their past tense (e.g., stretched-stretch) showed a reduction in the N400 negativity as well as a right frontotemporal positivity. In contrast, past tense priming for irregular verbs (e.g., fought-fight vs. sang-fight) showed a later-occurring right centroparietal positivity.

Finally, in a study on stem alternations in Spanish (Rodriguez-Fornells, Münte, \& Clahsen, 2002), the repe- tition of regular verbs that shared the same stem (e.g., ando-andar) produced the expected N400 reduction relative to an unrelated condition (e.g., ando-lavar; note that this study used an unrelated target as baseline and not, as usual, an unrelated prime). In contrast, irregular verbs with alternated stems (e.g., entiendo-entender vs. entiendo-querer) did not show any effects.

In many of these studies, an N400 reduction was taken to indicate that "regular verb forms can directly access their unmarked base forms as a result of morphological decomposition," and the lack of an N400 reduction to indicate that irregular verbs "form lexical entries separate from their corresponding base forms and can therefore access these only indirectly" (RodriguezFornells et al., 2002, p. 448). In these studies, similar to those using violation paradigms, other effects were left unexplained.

Although the above experiments contrasted two verb regularities and thus yielded binary results as evidence in favor of a dual-mechanism account, graded brain responses were observed as soon as more than two verb regularities were contrasted. Two recent repetitionpriming studies in English (Kielar \& Joanisse, 2009; Justus, Larsen, De Mornay Davies, \& Swick, 2008) compared the past tense priming by regular verbs (looked-look), weak/ suffixed irregulars (spent-spend), and strong/vowelchange irregulars (spoke-speak). In both studies, all three verb types showed N400 reductions for primed targets relative to unprimed targets as well as graded ERP effects between the verb regularities: In Justus et al., the priming of strong/vowel-change irregular verbs was stronger than that of weak/suffixed irregular or regular verbs in the late N400 ranges (between 500 and $700 \mathrm{msec}$ ). Although, in the opposite way, also Kielar and Joanisse (2009) found that the N400 effects were modulated in a graded way: strongest priming by regular verbs, weaker priming by strong/vowel-change irregulars, and an intermediate effect by weak/suffixed irregular verbs that were more similar to regular verbs. The authors of both studies concluded that there was no evidence for a categorical distinction between "regular" and "irregular," to the contrary, that the data are more consistent with single-system accounts, in particular, connectionist accounts.

To summarize, only one of the repetition-priming studies included an identity condition to measure full or partial priming, whereas five studies (including those proposing a dual-mechanism account) tested whether regularly and irregularly inflected verbs induce priming relative to an unrelated baseline. All besides one found rather similar ERP effects in the form of N400 deflections for regular and irregular verb forms. Hence, similar to violation paradigms, these effects are difficult to interpret as unequivocal categorical processing differences between regular and irregular verbs. To the contrary, the rather small differences may as well be interpreted to indicate continuous rather than categorical processing differences between regular and irregular verbs. 
Table 1. Summary of ERP Studies on Regular and Irregular Verb Inflection Using Grammatical Violations or Repetition Priming

\begin{tabular}{|c|c|c|c|c|c|c|c|c|}
\hline \multicolumn{9}{|c|}{ Grammatical Violations } \\
\hline Study & Language & Modality & Violation Type & Context & $\begin{array}{c}\text { Incorrect } \\
\text { Application of } \\
\text { Irregular Forms }\end{array}$ & $\begin{array}{l}\text { ERP Effects of } \\
\text { Regularization }\end{array}$ & $\begin{array}{c}\text { Incorrect } \\
\text { Application of } \\
\text { Irregular Forms }\end{array}$ & $\begin{array}{l}\text { ERP Effects of } \\
\text { Irregularization }\end{array}$ \\
\hline Allen et al., 2003 & English & visual & $\begin{array}{l}\text { past tense verb in } \\
\text { future context }\end{array}$ & sentence & will *worked vs. work & $\begin{array}{l}\text { late positivity (P600), } \\
\text { later onset than } \\
\text { irregular }\end{array}$ & will *stood vs. stand & late positivity (P600) \\
\hline Newman et al., 2007 & English & visual & $\begin{array}{l}\text { uninflected verb in } \\
\text { past tense context }\end{array}$ & sentence & $\begin{array}{l}\text { Yesterday I *frown } \\
\text { vs. frowned }\end{array}$ & $\begin{array}{l}\text { late positivity (P600) } \\
\text { and LAN }\end{array}$ & $\begin{array}{l}\text { Yesterday I *grind } \\
\text { vs. ground }\end{array}$ & $\begin{array}{l}\text { late positivity (P600) } \\
\text { and left (posterior) } \\
\text { negativity }\end{array}$ \\
\hline Penke et al., 1997 & German & visual & incorrect participle suffix & sentence & $\begin{array}{l}\text { *aufgeladet vs. } \\
\text { aufgeladen }\end{array}$ & LAN & $\begin{array}{l}\text { *durchgetanzen vs. } \\
\text { durchgetanzt }\end{array}$ & no effect \\
\hline \multirow[t]{2}{*}{ Gross et al., 1998} & Italian & visual & $\begin{array}{l}\text { incorrect theme vowel } \\
\text { and incorrect } \\
\text { participle suffix }\end{array}$ & sentence & *prend-a-to vs. preso & $\begin{array}{l}\text { N400 (lateralized to } \\
\text { the right temporal } \\
\text { region) }\end{array}$ & & \\
\hline & & visual & incorrect theme vowel & sentence & *dorm-a-to vs. dorm-i-to & no effect & *parl-i-to vs. parl-a-to & $\begin{array}{l}\text { right anterior negativity } \\
\text { at temporal sites }\end{array}$ \\
\hline \multirow[t]{3}{*}{$\begin{array}{l}\text { Rodriguez-Fornells } \\
\quad \text { et al., } 2001\end{array}$} & Catalan & visual & $\begin{array}{l}\text { incorrect theme vowel } \\
\text { and incorrect } \\
\text { participle suffix }\end{array}$ & sentence & *admet-a-t vs. admès & late positivity & & \\
\hline & & visual & incorrect theme vowel & sentence & *dorm-a-t vs. dorm-it & $\begin{array}{l}\text { left early (not anterior) } \\
\text { negativity and late } \\
\text { positivity }\end{array}$ & ${ }^{*}$ cant- $i-t$ vs. cant-a- $t$ & late positivity \\
\hline & & visual & incorrect theme vowel & sentence & $* t e m-a-t$ vs. $t e m-u-t$ & $\begin{array}{l}\text { left early (not anterior) } \\
\text { negativity and right } \\
\text { anterior negativity }\end{array}$ & & \\
\hline \multirow[t]{2}{*}{$\begin{array}{l}\text { Morris \& Holcomb, } \\
2005\end{array}$} & English & visual & $\begin{array}{l}\text { incorrect suffix and } \\
\text { incorrect stem } \\
\text { vowel }\end{array}$ & sentence & *bringed vs. brought & $\begin{array}{l}\text { LAN and late posterior } \\
\text { positivity (P600) }\end{array}$ & $\begin{array}{l}\text { *sept vs. walked } \\
\quad \text { (different verbs) }\end{array}$ & $\begin{array}{l}\text { LAN and late posterior } \\
\text { positivity ( } \mathrm{P} 600)\end{array}$ \\
\hline & & visual & $\begin{array}{l}\text { incorrect suffix and } \\
\text { incorrect stem } \\
\text { vowel }\end{array}$ & single words & *bringed vs. brought & $\begin{array}{l}\text { late (posterior) } \\
\text { positivity }\end{array}$ & $\begin{array}{l}\text { *sept vs. walked } \\
\quad \text { (different verbs) }\end{array}$ & late positivity \\
\hline
\end{tabular}


Table 1. (continued)

\begin{tabular}{|c|c|c|c|c|c|c|c|c|c|}
\hline \multicolumn{10}{|c|}{ Repetition Priming } \\
\hline Study & Language & $\begin{array}{c}\text { Type } \\
\text { of Priming }\end{array}$ & Modality & Comparison & Context & $\begin{array}{l}\text { Regular Prime- } \\
\text { Target Pairs }\end{array}$ & $\begin{array}{c}\text { ERP Effects of } \\
\text { Regular Repetition }\end{array}$ & $\begin{array}{c}\text { Irregular } \\
\text { Prime-Target Pairs }\end{array}$ & $\begin{array}{c}\text { ERP Effects of } \\
\text { Irregular Repetition }\end{array}$ \\
\hline \multirow[t]{2}{*}{$\begin{array}{l}\text { Weyerts et al., } \\
1996\end{array}$} & German & long lag & visual & $\begin{array}{l}\text { unprimed vs. } \\
\text { identity }\end{array}$ & single words & $\begin{array}{l}\text { getanzt (unprimed) } \\
\text { vs. getanzt-getanzt }\end{array}$ & $\begin{array}{l}\text { N400 and post- } \\
\text { N400 range }\end{array}$ & $\begin{array}{l}\text { geboten (unprimed) } \\
\text { vs. geboten-geboten }\end{array}$ & $\begin{array}{l}\text { N400, later onset } \\
\text { than regular }\end{array}$ \\
\hline & & long lag & visual & $\begin{array}{l}\text { unprimed vs. } \\
\text { infinitive }\end{array}$ & single words & $\begin{array}{l}\text { getanzt (unprimed) } \\
\quad \text { vs. tanzen-getanzt }\end{array}$ & $\begin{array}{l}\text { N400 and post- } \\
\text { N400 range }\end{array}$ & $\begin{array}{l}\text { geboten (unprimed) } \\
\text { vs. bieten-geboten }\end{array}$ & $\begin{array}{l}\text { N400, later onset } \\
\text { than regular }\end{array}$ \\
\hline $\begin{array}{l}\text { Münte et al., } \\
1999\end{array}$ & English & long lag & visual & $\begin{array}{l}\text { unrelated vs. } \\
\text { past tense }\end{array}$ & single words & $\begin{array}{l}\text { walked-stretch vs. } \\
\text { stretched-stretch }\end{array}$ & $\begin{array}{l}\text { N400 and right } \\
\text { fronto-temporal } \\
\text { positivity }\end{array}$ & $\begin{array}{l}\text { sang-fight vs. } \\
\text { fought-fight }\end{array}$ & $\begin{array}{l}\text { right centroparietal } \\
\text { positivity }\end{array}$ \\
\hline $\begin{array}{l}\text { Marslen-Wilson } \\
\text { \& Tyler, } 1998\end{array}$ & English & immediate & cross-modal & $\begin{array}{l}\text { unrelated vs. } \\
\text { past tense }\end{array}$ & single words & $\begin{array}{l}\text { locked-jump vs. } \\
\text { jumped-jump }\end{array}$ & N400 and LAN & $\begin{array}{l}\text { shows-find vs. } \\
\text { found-find }\end{array}$ & N400 and LAN \\
\hline $\begin{array}{l}\text { Rodriguez-Fornells } \\
\text { et al., } 2002\end{array}$ & Spanish & long lag & visual & $\begin{array}{l}\text { unrelated vs. } \\
\text { present tense }\end{array}$ & single words & $\begin{array}{l}\text { ando-lavar vs. } \\
\text { ando-andar }\end{array}$ & N400 & $\begin{array}{l}\text { entiendo-querer vs. } \\
\text { entiendo-entender }\end{array}$ & no effect \\
\hline \multirow[t]{2}{*}{$\begin{array}{l}\text { Justus et al., } \\
2008\end{array}$} & English & immediate & auditory & $\begin{array}{l}\text { unrelated vs. } \\
\text { past tense }\end{array}$ & single words & $\begin{array}{l}\text { worked-seem vs. } \\
\text { looked-look }\end{array}$ & $\begin{array}{l}\text { N400 and } \\
\text { late N400 }\end{array}$ & $\begin{array}{l}\text { suffixed irregular: } \\
\text { had-fight vs. } \\
\text { slept-sleep }\end{array}$ & $\mathrm{N} 400$ and late $\mathrm{N} 400$ \\
\hline & & & & & & & & $\begin{array}{l}\text { vowel change irregular: } \\
\text { bound-wake vs. } \\
\text { spoke-speak }\end{array}$ & $\begin{array}{l}\text { N400, late N400 } \\
\text { (strongest priming } \\
\text { effect) }\end{array}$ \\
\hline \multirow[t]{4}{*}{$\begin{array}{l}\text { Kielar \& Joanisse, } \\
2009\end{array}$} & English & immediate & visual & $\begin{array}{l}\text { unrelated vs. } \\
\text { past tense }\end{array}$ & single words & $\begin{array}{l}\text { rented-walk vs. } \\
\text { walked-walk }\end{array}$ & $\begin{array}{l}\text { N400 (strongest } \\
\text { priming effect) }\end{array}$ & $\begin{array}{l}\text { suffixed irregular: } \\
\text { wept-feel vs. } \\
\text { felt-feel }\end{array}$ & $\begin{array}{l}\text { N400 (intermediate } \\
\text { priming effect) }\end{array}$ \\
\hline & & & & & & & & $\begin{array}{l}\text { vowel change irregular: } \\
\text { sang-write vs. } \\
\text { wrote-write }\end{array}$ & $\begin{array}{l}\text { N400 (weakest } \\
\text { priming effect) }\end{array}$ \\
\hline & & immediate & cross-modal & $\begin{array}{l}\text { unrelated vs. } \\
\text { past tense }\end{array}$ & single words & $\begin{array}{l}\text { rented-walk vs. } \\
\text { walked-walk }\end{array}$ & $\begin{array}{l}\text { N400 (strongest } \\
\text { priming effect) }\end{array}$ & $\begin{array}{l}\text { suffixed irregular: } \\
\text { wept-feel vs. } \\
\text { felt-feel }\end{array}$ & $\begin{array}{l}\text { N400 (intermediate } \\
\text { priming effect) }\end{array}$ \\
\hline & & & & & & & & $\begin{array}{l}\text { vowel change irregular: } \\
\text { sang-write vs. } \\
\text { wrote-write }\end{array}$ & $\begin{array}{l}\text { N400 (weakest } \\
\text { priming effect) }\end{array}$ \\
\hline
\end{tabular}




\section{Experiment}

The purpose of the above summary of ERP studies was to demonstrate that regular and irregular verb inflections elicit the most diverse effects in the violation paradigm and rather similar effects within the repetition-priming paradigm. Neither the diversity nor the similarities have been adequately considered in interpretations and the inconsistencies cast doubt on a straightforward support of either a dual- or a single-mechanism account.

Most repetition-priming studies have been conducted in English where several factors relating to inflectional morphology, such as suffixation and stem preservation, are confounded. In this respect, German participle formation is particularly interesting. First, it is concatenative for both regular and irregular types: All participles comprise the ge- prefix, a stem (with or without vowel change), and a suffix (-t or -en; see Table 2). Second, it allows us to test gradation between complete regularity and complete irregularity: Regular participles comprise the regular (unchanged infinitive) stem and the regular - $t$ suffix, semiirregular participles comprise the (unchanged) stem and the irregular -en suffix, and completely irregular participles comprise a stem with vowel change and the en suffix. We labeled these three verb types "regular," "irregular 1," and "irregular 2," respectively, following the study of Smolka, Zwitserlood, and Rösler (2007). We refer to that study for a detailed description of German participle formation.

Within the domain of repetition-priming studies, we are aware of only one ERP study and one behavioral experiment that examined regular and irregular participles in German. The ERP study (Weyerts et al., 1996) is described above; the behavioral study, in the following. Using cross-modal priming, Sonnenstuhl, Eisenbeiss, and Clahsen (1999) contrasted the priming by "regular" and "irregular 1" participles, which both keep the stem unchanged and differ in the suffix (-t and -en, respectively). Targets were inflected verbs in the first-person singular present (stem/-e suffix) that were preceded either by themselves, by their participle, or by an unrelated inflected form (stem/-e suffix). Regular participles (e.g., gekauft-kaufe) induced the same amount of priming to the first person inflection as did identity primes (kaufe-kaufe). By contrast, irregular participles (e.g., gelaufen-laufe) induced less priming than the identical verb forms (laufe-laufe). In line with a dual-mechanism account, this was interpreted to indicate full priming for regular verbs and partial priming for irregular verbs.

However, as we have previously argued (Smolka et al., 2007), a closer look at their results (see Table 2 in Sonnenstuhl et al., 1999) shows that relative to the unrelated condition, the participle priming by "irregular 1 " verbs ( $25 \mathrm{msec}$ ) was equivalent to that by "regular" verbs (30 msec). The critical interaction rather resulted from stronger identity priming by "irregular 1" verbs (57 msec) than by "regular" verbs (30 msec), which may have been a confound of lexical frequency (with "irregular 1" verbs being of higher frequency than "regular" verbs) rather than the reflection of two different processing systems. ${ }^{2}$

Nevertheless, these priming differences were taken as evidence for radically different processing systems, namely a default system that generates regular participles from stems and a memory system that stores the wholeword forms of irregular participles. Our aim was to go beyond stating a mere difference between regular and irregular verbs and rather to investigate whether the linguistic categories of regular versus irregular are processed continually within the same system or by categorically distinct systems.

For this purpose, we included three verb regularities to tap into graded processing, that is, in addition to the contrast of regular and irregular ("regular" vs. "irregular 1" in Sonnenstuhl et al., 1999; "regular" vs. "irregular 2" in Weyerts et al., 1996), we included "regular," "irregular 1," and "irregular 2" participles ("irregular 3" verbs were not included because of their low type frequency; see Table 2). Most repetition-priming studies measured verb priming relative to an unrelated baseline (see Kielar \& Joanisse, 2009; Justus et al., 2008; Rodriguez-Fornells et al., 2002; Münte et al., 1999; Marslen-Wilson \& Tyler, 1998). We also used an identity condition against which we measured full and partial priming (see Table 3 for all prime conditions and examples of stimuli).

Table 2. German Participle Formation According to Stem and Suffix Combinations

\begin{tabular}{|c|c|c|c|c|c|}
\hline Verb Type & Citation Form & Participle & Stem & Suffix & $n$ \\
\hline Regular & lernen (learn) & gelernt & infinitive & $-t$ & 1700 \\
\hline Irregular 1 & backen (bake) & gebacken & infinitive & en & 41 \\
\hline Irregular 2 & trinken (drink) & getrunken & vowel change & en & 144 \\
\hline Irregular 3 & denken (think) & gedacht & vowel change & $-t$ & 15 \\
\hline
\end{tabular}

Regular and irregular participle formation is concatenative and shows the same affixation: The prefix ge- and one of two suffixes, $-t$ or -en, are attached to a stem. The prefix ge- is used for all verb types; its distribution is exclusively prosodically conditioned (Wiese, 1996). All examples are given in their orthographic form, hence -en suffix, and not in their phonetic form, where the letter $e$ is realized as schwa or is not realized at all. $n=$ type count of monomorphemic verbs in CELEX (Baayen et al., 1993). 
Table 3. Examples of Verb Targets and Corresponding Primes

\begin{tabular}{lcccccc}
\hline Verb Class & Target & $I$ & $P$ & $S$ & $S P$ & $U$ \\
\hline Regular & lerne (learn) & lerne (learn) & gelernt (learned) & büffle (cram) & gebüffelt (crammed) & trockne (dry) \\
Irregular 1 & backe (bake) & backe (bake) & gebacken (baked) & koche (cook) & gekocht (cooked) & winke (wave) \\
Irregular 2 & trinke (drink) & trinke (drink) & getrunken (drunk) & saufe (booze) & gesoffen (boozed) & fahnde (search) \\
\hline
\end{tabular}

$\mathrm{I}=$ identity prime; $\mathrm{P}=$ participle of the target; $\mathrm{S}=$ semantic associate in the same inflection as the target; $\mathrm{SP}=$ semantic associate in the participle inflection; $\mathrm{U}=$ unrelated. English translations are in parentheses.

We further introduced a semantic condition to directly measure whether participle priming substantially differs from that between semantic associates (see also Table 3). Semantic priming is usually examined by means of semantically associated noun pairs, such as cherry-grape and queen-king (see Kielar \& Joanisse, 2009; Marslen-Wilson \& Tyler, 1998), which are different in many respects, notably word class, from the inflected verbs used in the morphologically relevant conditions. We therefore used inflected verbs that are semantically related with the target, such as schmecke-rieche ("taste-smell," both in first person inflection) and beginne-starte ("begin-start," both in first person inflection). Using a within-target manipulation, we could thus directly compare the effect of the participle (e.g., getrunken, "drunk") with that of the semantically related verb (e.g., saufe, "booze") or its participle (e.g., gesoffen, "boozed") on the same verb target (e.g., trinke, "drink").

Concerning the possible electrophysiological correlates of morphological and semantic processing, we build on the notion that these are separable cognitive processes that are reflected by different electrophysiological correlates. Generally, there are two fundamental findings in psycholinguistic EEG research: (1) differences in semantic processes are most often reflected in modulations of the N400 effect, whereas (2) differences because of grammatical processing are most often reflected in modulations of the LAN and P600 components (for an overview, see Kutas \& Federmeier, 2007). On the basis of these considerations, we elaborate the experimental hypotheses based on a dual-mechanism account in contrast to those based on a single-system account as suggested in Smolka et al. (2007).

\section{Is Participle Priming Different for Regular and Irregular Verbs?}

This question is usually examined by assessing whether regular and irregular participles facilitate the recognition of their base verbs relative to an unrelated baseline (see Kielar \& Joanisse, 2009; Justus et al., 2008; RodriguezFornells et al., 2002; Münte et al., 1999). The question relates to the assumptions of dual-mechanism models that regular inflection is parsed within a procedural system (e.g., in Broca's area, see Ullman et al., 1997), whereas irregular inflection is stored in declarative memory. Accord- ingly, the parsing of regular forms should be reflected in syntactic processing components like the LAN and/or $\mathrm{P} 600$, whereas the retrieval of irregular whole-word forms should be reflected in processing components that are considered typical for lexical semantics like the N400.

Most importantly, dual-mechanism models maintain a dichotomous differentiation between a regular system and an irregular system-independent of the "amount of irregularity"- and thus predict parsing effects for "regular" participles in contrast to similar retrieval effects for "irregular 1" and "irregular 2" subgroups (cf. Clahsen, Prüfert, Eisenbeiss, \& Cholin, 2002). ${ }^{3}$

If, however, regular and irregular participles are stored and processed within the same system, we should find graded effects of participle priming between "regular," "irregular 1," and "irregular 2" participles. Graded effects may surface via amplitude, latency, or topography. In associative semantic-network models similar to that by Collins and Loftus (1975; Dell, 1986; for different accounts, see, e.g., Brunel \& Lavigne, 2009; Bodner \& Masson, 2003), activation spreads from the activated node (i.e., a heard or seen word or concept) to other nodes in the network: The stronger the activation of the first node, the stronger the activation of the surrounding nodes and the further the spread of activation through the network. On the basis of the assumptions of semantic-network models as well as on previous findings of graded priming effects in English (e.g., Kielar \& Joanisse, 2009), we expected graded changes of the N400 modulations in terms of both amplitude and scalp distribution (reflecting the strength and distribution of activation, respectively).

We have previously observed that both regular and irregular participles are decomposed and accessed for their stems (Smolka et al., 2007; Smolka, 2005). Differences between verb regularities may emerge because of differences in stem connectivity with inflectional forms: "Regular" participles hold a stem that occurs, by definition, in all verb inflections; "irregular 1" participles have a stem that occurs in fewer verb inflections; and "irregular 2" stems have stems that occur, at least, sometimes only in the participle form. The differences in stem connectivity across the verb regularities may thus surface in graded N400 amplitude as well as scalp distribution: from strongest and most widely distributed to weakest effects in both amplitude and topography for "regular," "irregular 1," and "irregular 2" verbs, respectively. 


\section{Is Participle Priming Full or Partial?}

This question is usually examined by assessing the amount of participle priming relative to identity priming (see Sonnenstuhl et al., 1999; Weyerts et al., 1996). The question relates to the assumption of dual-mechanism models (e.g., Clahsen et al., 2002) that, in the regular system, only the base has a lexical entry, which is shared by all other regularly inflected forms. Before memory access, regular participles (in German, those with the regular $-t$ suffix) are parsed into base and suffix so that only the base is accessed. The priming because of regular participles thus relies on the activation of the same base as that because of identity primes and should be full, namely equivalent to that because of identity priming. By contrast, because "irregular 1" and "irregular 2" participles do not take the "regular" $-t$ suffix, these forms are expected to be retrieved as whole-word units, so that the priming of irregular participles relies on the activation of related entries in a semantic network. The amount of participle priming should thus be partial, that is, less than identity priming. This dual-mechanism argument thus predicts an interaction between verb regularity and priming pattern: "Regular" participles should yield full priming, whereas "irregular 1" and "irregular 2" participles should produce partial priming. If, however, all regular and irregular participles are parsed and accessed for their stem, as assumed by Smolka et al. (2007), this will yield similar priming patterns for the three subtypes of verb regularity.

\section{Is Semantic Priming Different for Regular and Irregular Verbs?}

There is recent evidence that English regular and irregular verbs differ not only with respect to their affixation but also with respect to several semantic factors (e.g., Baayen \& Moscoso del Prado Martin, 2005; Davis, Meunier, \& Marslen-Wilson, 2004; Ramscar, 2002). For example, Baayen and Moscoso del Prado Martin (2005) compared the attributes of about 1,500 regular and 150 irregular English mono-morphemic verbs and observed that irregular verbs were more semantically rich in that they had stronger and more semantic interconnections with other words than did regular verbs.

To address the question whether regular and irregular verbs differ with respect to semantic processing, we used semantic verb associates as semantic primes to the inflected verb targets, such as zable-kaufe ("pay-buy") and unterstütze-helfe ("support-help").

In the ERP literature, the N400 is regarded to be very sensitive to the semantic proximity of words (and their concepts) in the semantic network (for a review, see Kutas \& Federmeier, 2000, 2007; for word pairs: Bentin et al., 1985). For example, Rösler and colleagues (Khader, Scherag, Streb, \& Rösler, 2003; Rösler, Streb, \& Haan, 2001) found a reduced $\mathrm{N} 400$ for semantically associated verbs relative to unrelated verbs. We thus expect N400 effects for verbs primed by semantically related associates (relative to unrelated verbs), and these N400 effects should differ if semantic priming indeed differed between regular and irregular verbs.

\section{Is Participle Priming Different from Semantic Priming?}

Dual-mechanism accounts assume that irregular participles have their own representation in associative memory. If the priming of irregular participles relies on the activation of related entries in an associative network, irregular participles should induce priming that is similar to that of semantically related verbs. By contrast, if the priming of regular participles relies on a parsing procedure within a procedural system, the priming of regular participles should differ from that in a semantic associative network (cf. Rodriguez-Fornells et al., 2002). To provide a direct comparison of participle and semantic priming, each target (e.g., kaufe, "buy") was combined with its participle (gekauft, "bought") and with a semantically associated prime in participle form (gezahlt, "paid").

We have previously shown that verbs containing the same stem induce stronger priming than verbs holding different stems, even if the latter are strongly semantically related (zerbersten-brechen, "burst-break"), whereas the former are not (verbrechen-brechen, "commit a crimebreak"; Smolka, Preller, \& Eulitz, under revision; Smolka, Komlósi, \& Rösler, 2009). We thus expected that the priming of verb targets by their own (regular and irregular) participles will be stronger (at least different) than that by purely semantically related verbs.

To avoid any confound between brain responses and overt response preparation (for the lexical decisions), we collected electrophysiological and behavioral responses in two separate experiments (see below).

\section{METHODS}

\section{Participants}

Fifteen and twenty-two students at Marburg University participated in the EEG and the RT experiments, respectively, and were paid for their participation. All were monolingual native speakers of German, were not dyslexic, and reported normal or corrected-to-normal vision. All participants of the EEG experiment were right-handed.

\section{Materials}

The materials were the same for the EEG and the behavioral study.

\section{Verb Stimuli}

The critical stimuli consisted of 132 German monomorphemic verbs; half were regular, and the other half 
were irregular. Of the irregular ones, 22 were of the "irregular 1" type (infinitive stem/-en suffix) and 44 were of the "irregular 2" type (vowel change/-en suffix; see Table 2). To avoid any confusion with the participle prefix ge-, none of the verbs began with the letters ge- in the infinitive.

Stimuli were matched on participle frequency according to CELEX (Baayen, Piepenbrock, \& Van Rijn, 1993). The mean participle frequency (per million) was 19 for "regular" verbs, 33 for "irregular 1" verbs, and 25 for "irregular 2" verbs. Targets were presented either in the first person (stem/-e suffix) or the second person (stem/-st suffix) inflection, equally often within each set of verb regularity. Potential homographs to nouns (e.g., folge, "I follow," vs. Folge, "sequence" [noun]) were always used in the second person, as the -st suffix does not occur in noun inflection.

Each verb target was combined with five primes (see Table 3): (1) the target itself (identity condition, I), (2) its participle (participle condition, $\mathrm{P}$ ), a semantic associate in either (3) the same inflection as the target (semantic condition, S) or (4) the participle formation (semantic participle condition, SP), and (5) an unrelated condition in the same inflection as the target (unrelated condition, $\mathrm{U}$ ).

\section{Semantic Association Test}

A semantic association test was conducted to establish the relatedness between primes and targets for the semantically related and unrelated prime conditions. For each of the 132 verb targets, the selected semantically related and unrelated verbs were distributed across two lists, so that each list contained only one prime for the same target verb. The verb intended as the prime preceded the target, and both were presented in citation form (stem/-en suffix). Thirty-four participants who did not take part in the experiment proper rated the relationship between the verbs of each pair on a 7-point scale from completely unrelated (1) to bighly related (7). Mean ratings for semantically related pairs were 5.92 for regular verbs, 5.95 for "irregular 1," and 5.94 for "irregular 2" verbs; and mean ratings for unrelated pairs were 1.61, 1.33, and 1.48 for "regular," "irregular 1," and "irregular 2" verbs, respectively. A two-way ANOVA with between-items factor of verb regularity ("regular"/“irregular 1"/"irregular 2") and repeated measures factor of relatedness (semantic/ unrelated) was run on mean ratings. Only the effect of relatedness was significant, $F(1,129)=2262.81, p<.0001$, indicating that the ratings were significantly higher for semantically associated than for unrelated verbs and did not differ across verb regularities.

Given that the semantic associates had lower frequencies than the target verbs, the frequencies of the unrelated primes (and their participles) were matched to those of the semantic primes (and their participles). Mean (participle) frequency (per million) was 14.6 for semantic primes and 15.2 for unrelated primes to regular verb targets and 8.2 and 10.3 for semantic and unrelated primes to irregular verb targets, respectively.

\section{Orthographic Overlap}

Orthographic overlap is usually defined as the number of letters shared in the same position between prime and target (starting from left to right), divided by the number of letters in the longer word (e.g., Pastizzo \& Feldman, 2002). Mean orthographic overlap between semantic primes (S) and inflected targets was 8.0\%, 13.5\%, and 8.3\% for "regular," "irregular 1," and "irregular 2" verbs, respectively, and similar to that between unrelated primes (U) and inflected targets with 8.5\%, 9.3\%, and 10\%, respectively. Mean orthographic overlap between participle primes (P) and inflected targets was $4.6 \%$ for "regular" verbs, $1.9 \%$ for "irregular 1" verbs, and $2.8 \%$ for "irregular 2" verbs and similar to the overlap between semantic participle primes (SP) and targets: $4.3 \%, 2.3 \%$, and $4.9 \%$, respectively.

Because this count of orthographic overlap does not take into account that the stem is preceded by the letter cluster ge- in the participle formation but not in the first person inflection, we calculated the orthographic overlap between participle primes and inflected targets when participles were stripped of the ge-prefix, so that the orthographic overlap between participle and inflected target like getrunken ("drunk") and trinke ("drink") was 5 of 7 (i.e., 71\%). In this count, mean orthographic overlap between participle primes and inflected targets was 81.4\% for "regular" verbs, 69.4\% for "irregular 1" verbs, and $49.0 \%$ for "irregular 2" verbs. Note, however, that this count makes the assumption that all participles-both regular and irregular ones-are decomposed into stem and affixes.

\section{Pseudoverb Stimuli}

The critical set was complemented by an equivalent number of prime-target pairs with pseudoverbs as targets (in the first or second person inflection). Pseudoverbs were constructed by exchanging one or two letters in real verbs, while preserving the phonotactic constraints of German.

\section{Apparatus}

In both the EEG and behavioral experiments, stimuli were presented on a 17-in. monitor, connected to an IBM-compatible Pentium III personal computer. Stimulus presentation was controlled by the Presentation software (nbs.neuro-bs.com). Response latencies were recorded from the left and right "control" keyboard keys.

\section{Procedure}

To conduct an experiment with both within-subject and within-target design, each participant saw each target with five different primes. The different prime conditions of the same target were evenly allocated to blocks (see 
below), so that any possible effect of target repetition was equally balanced across conditions. ${ }^{4}$

Each participant saw all 132 verbs in all five prime conditions (altogether 660 prime-target pairs). Primes of the same target were rotated over five blocks according to a Latin Square design; the prime-pseudoverb targets were equally distributed across the blocks. In total, an experimental session comprised 1,320 prime-target pairs, 264 pairs per block. Prime-target pairs within a block were randomized separately for each participant. There were 16 practice trials.

Participants were tested individually, seated at a viewing distance of about $60 \mathrm{~cm}$ from the screen. Stimuli were presented in the center of the screen, in white Sans-Serif letters, point 20, on a black background. Primes were presented in uppercase letters; targets, in lowercase. The prime appeared for $50 \mathrm{msec}$, followed by a blank screen for $40 \mathrm{msec}(\mathrm{SOA}=90 \mathrm{msec})$, immediately followed by the presentation of the target. In the EEG experiment, the target was presented for $1000 \mathrm{msec}$, followed by a question mark as response prompt. Participants were instructed to refrain from blinking until after the prompt and to subsequently make their lexical decision as accurately as possible. In the RT experiment, the target was presented for $500 \mathrm{msec}$, followed by a blank screen until a participant's response. Participants were instructed to make their lexical decisions as fast and correct as possible. The intertrial interval was 2000 msec. "Word" responses were given with the index finger of the right/dominant hand; those for "pseudoword," with the left/subordinate hand. The experiment proper lasted for about $90 \mathrm{~min}$. Participants took several breaks in-between blocks.

\section{EEG Recording and Analysis}

The EEG was recorded in direct-current (DC) mode from $61 \mathrm{Ag}-\mathrm{AgCl}$ scalp electrodes (EasyCap System, Herrsching, Germany). All scalp electrodes were referenced to one earlobe during the recording and rereferenced off-line to averaged earlobes. The horizontal and vertical EOG was monitored with appropriate electrode pairs. Impedances were kept below $5 \mathrm{k} \Omega$. Two 32-channel amplifiers (SYNAMPS, NeuroScan, Singen, Germany) were used for EOG and EEG recording. Band pass was set from DC to $40 \mathrm{~Hz}$, and the sampling rate was $500 \mathrm{~Hz}$. The left or right mastoid (counterbalanced across participants) served as ground. Electrophysiological data collection was done by the NeuroScan software Acquire. Before each experimental block, a DC reset was initiated manually. DC drift was corrected according to the method suggested by Hennighausen, Heil, and Rösler (1993). Eye blinks and trials with other artifacts were removed by applying a threshold criterion (maximum voltage range within a trial segment should be lower than $150 \mu \mathrm{V}$ ). ERPs were extracted by averaging single trials separately for participants, electrodes, and experimental conditions. Average voltage amplitudes were computed for consecutive intervals of
30 msec width, beginning at the onset of the target word and ending $900 \mathrm{msec}$ later. Poststimulus intervals were baseline-adjusted to the average amplitude of a 100-msec interval preceding the onset of the prime word. A subset of electrodes resembling the 19 standard electrodes of the 10-20 system entered the statistical analysis (see Figure 1). This reduction of electrodes reduces the number of degrees of freedom in the ANOVA and thus provides more conservative tests for the interactions of the electrode factor, although, at the same time, it preserves the topographical information.

The statistical analyses of the effects of interest included separate ANOVAs for each of the 30 time intervals (of 30 msec each), including the relevant prime conditions as one experimental factor as well as the factors regularity and electrodes. Factor regularity always comprised three levels ("regular," "irregular 1," and "irregular 2"), and factor electrodes comprised 19 levels (Fp1, Fp2, F7, F3, Fz, F4, F8, T3, C3, Cz, C4, T4, P3, Pz, P4, T5, O1, O2, and T6). ${ }^{5}$ Following the hierarchical testing procedure (as outlined, e.g., in Rösler, Friederici, Pütz, \& Hahne, 1993), in a second step, differences between experimental factors were tested with local $t$ tests for each electrode, if the timepoint-specific ANOVA had signaled interactions with the electrode factor. Alpha error was further reduced by regarding only those effects as substantial that were significant $(p<.05)$ during at least two consecutive time windows. All factors were defined as repeated measures. Probabilities of observed $F$ ratios were adjusted according to Huynh and Feldt (1976). In contrast to most EEG studies on language processing that examine predefined electrode clusters (e.g., left vs. right hemisphere, anterior vs. posterior) and large time windows (e.g., 300-500 msec), in this

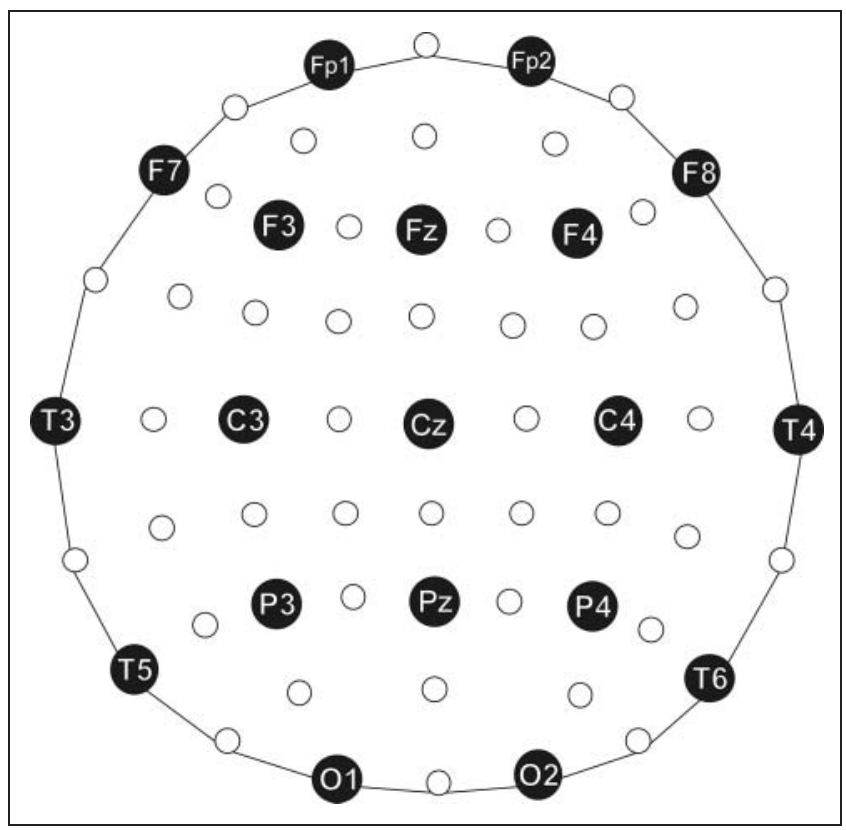

Figure 1. Electrode montage. The 19 electrodes of the 10-20 system were used in the analyses of the EEG data. 
study, the statistical analyses of the EEG data were a priori restricted to neither specific electrodes (or electrode clusters) nor time windows. Therefore, this procedure provides a more comprehensive evaluation of possible graded processing as reflected in graded potentials and allows for an unbiased assessment of the complete spatio-temporal structure of the electrophysiological response.

\section{RESULTS}

Results are reported according to our experimental questions and hypotheses. For a direct comparison, the behav- ioral analyses were conducted in line with the ERP analyses. In all analyses, all variables were treated as repeated measures factors. Only significant effects are reported. The statistics for all ERP effects are summarized in Table 4; RT means are provided in Table 5.

\section{ERP Results}

The effects of verb regularity regarding morphological priming are usually investigated by two different questions: First, did participles induce priming relative to an unrelated condition? Second, was the amount of participle priming full or partial relative to the identity condition?

Table 4. Summary of ERP Effects

\begin{tabular}{|c|c|c|c|c|c|c|}
\hline Analysis & Effect & Time Windows & $d f$ & $F^{a}$ & $p$ & $\varepsilon$ \\
\hline \multicolumn{7}{|c|}{ Is Participle Priming Different for Regular and Irregular Verbs? } \\
\hline \multirow{7}{*}{$\begin{array}{l}\text { Regularity (regular/irregular 1/irregular 2) } \times \\
\text { Relatedness (participle/unrelated) } \times \text { Electrode }\end{array}$} & \multirow[t]{2}{*}{ Relatedness } & \multirow[t]{2}{*}{$240-480 \mathrm{msec}$} & 1,14 & 4.83 & .0454 & \\
\hline & & & 1,14 & 13.27 & .0027 & \\
\hline & \multirow[t]{3}{*}{ Relatedness $\times$ Electrode } & $210-360 \mathrm{msec}$ & 18,252 & 2.39 & .0419 & .210 \\
\hline & & $420-510 \mathrm{msec}$ & & & & \\
\hline & & $600-720 \mathrm{msec}$ & 18,252 & 6.71 & $<.0001$ & .204 \\
\hline & \multirow{2}{*}{$\begin{array}{l}\text { Regularity } \times \text { Relatedness } \times \\
\text { Electrode }\end{array}$} & \multirow[t]{2}{*}{ 390-480 msec } & 36,504 & 2.31 & .0473 & .152 \\
\hline & & & 36,504 & 3.03 & .0081 & .178 \\
\hline \multirow{2}{*}{$\begin{array}{l}\text { Regularity (regular/irregular } 2) \times \text { Relatedness } \\
\quad(\text { participle/unrelated) } \times \text { Electrode }\end{array}$} & Relatedness & $200-550 \mathrm{msec}$ & 1,14 & 17.43 & $<.0001$ & \\
\hline & Relatedness $\times$ Electrode & $200-550 \mathrm{msec}$ & 18,252 & 4.57 & .0507 & \\
\hline \multicolumn{7}{|l|}{ Is Participle Priming Full or Partial? } \\
\hline \multirow{4}{*}{$\begin{array}{l}\text { Regularity (regular/irregular 1/irregular 2) } \times \\
\text { Relatedness (participle/identity) } \times \text { Electrode }\end{array}$} & \multirow[t]{2}{*}{ Relatedness } & \multirow[t]{2}{*}{$360-480 \mathrm{msec}$} & 1,14 & 4.73 & .0473 & \\
\hline & & & 1,14 & 12.42 & .0034 & \\
\hline & \multirow[t]{2}{*}{ Relatedness $\times$ Electrode } & \multirow[t]{2}{*}{ 360-690 msec } & 18,252 & 3.16 & .0108 & .208 \\
\hline & & & 18,252 & 5.99 & .0006 & .164 \\
\hline \multicolumn{7}{|c|}{ Is Semantic Priming Different for Regular and Irregular Verbs? } \\
\hline \multirow{4}{*}{$\begin{array}{l}\text { Regularity (regular/irregular 1/irregular 2) } \times \\
\text { Relatedness (identity/semantic/unrelated) } \times \\
\text { Electrode }\end{array}$} & \multirow[t]{2}{*}{ Relatedness } & \multirow[t]{2}{*}{$240-510 \mathrm{msec}$} & 2,28 & 3.85 & .0334 & .984 \\
\hline & & & 2,28 & 34.12 & $<.0001$ & .916 \\
\hline & \multirow[t]{2}{*}{ Relatedness $\times$ Electrode } & \multirow[t]{2}{*}{$300-540 \mathrm{msec}$} & 36,504 & 3.80 & .0005 & .141 \\
\hline & & & 36,504 & 6.56 & $<.0001$ & .122 \\
\hline \multicolumn{7}{|c|}{ Is Participle Priming Different from Semantic Priming? } \\
\hline \multirow{2}{*}{$\begin{array}{l}\text { Regularity }(\text { regular/irregular 1/irregular 2) } \times \\
\text { Relatedness }(\mathrm{P}-\mathrm{I} / \mathrm{SP}-\mathrm{S}) \times \text { Electrode }\end{array}$} & \multirow[t]{2}{*}{ Relatedness $\times$ Electrode } & \multirow[t]{2}{*}{ 360-390 msec } & 18,252 & 2.56 & .0321 & .2912 \\
\hline & & & 18,252 & 3.41 & .0092 & .2664 \\
\hline \multirow{2}{*}{$\begin{array}{l}\text { Regularity (regular/irregular 1/irregular 2) } \times \\
\text { Relatedness }(\mathrm{P}-\mathrm{U} / \mathrm{SP}-\mathrm{U}) \times \text { Electrode }\end{array}$} & \multirow[t]{2}{*}{ Relatedness } & \multirow[t]{2}{*}{ 360-420 msec } & 1,14 & 6.48 & .0233 & \\
\hline & & & 1,14 & 9.58 & .0079 & \\
\hline
\end{tabular}

${ }^{\mathrm{a}}$ Minimum and maximum $F$ s referring to the smallest and largest $F$ values within the significant time interval. Minimum $F$ s are provided in the upper row; maximum Fs are in the lower row of each effect. 
Table 5. Mean RTs in msec $(S D)$ as Responses to Regular, Irregular 1, and Irregular 2 Verb Targets Preceded by Different Types of Prime

\begin{tabular}{llcccrc}
\hline Verb Class & Target & $I$ & $P$ & $S$ & $S P$ \\
\hline Regular & lerne (learn) & $603(104)$ & $623(106)$ & $641(99)$ & $650(104)$ & $662(104)$ \\
Irregular 1 & backe (bake) & $587(102)$ & $627(118)$ & $631(102)$ & $647(99)$ & $642(93)$ \\
Irregular 2 & trinke (drink) & $596(98)$ & $621(105)$ & $628(110)$ & $634(96)$ & $635(94)$ \\
\hline
\end{tabular}

To answer these questions, we conducted the following two analyses.

\section{Is Participle Priming Different for Regular and Irregular Verbs?}

To evaluate whether regular and irregular participles yield different amounts of priming, an ANOVA was computed with the factors Relatedness (participle/unrelated), Regularity, and Electrodes. This analysis revealed a significant main effect of Relatedness for time intervals of 240-480 msec. The interaction between Relatedness and Electrodes was significant for the time intervals 210-360, 420-510, and 600-720 msec and indicated that, between 210 and 510 msec after target onset, ERPs to targets were more negative when preceded by an unrelated verb than when preceded by their participle. From 210 to $360 \mathrm{msec}$, this effect was reliable at all frontal and central electrodes as well as at T3. In contrast, the later interaction from 420 to $510 \mathrm{msec}$ indicated a shift toward more posterior electrode sites, with significant differences at F3, C3, C4, Cz, P3, Pz, O1, T3, and T5. The interaction from 600 to $720 \mathrm{msec}$, however, indicated the reverse effect: Unrelated primes produced more positive potentials than participle primes, which is because of a latency difference between the two N400 components (see Figure 2) and significant only at F4, C4, and Cz.

Figure 2 depicts the grand averages of the participle primes (e.g., gekauft-kaufe, "bought-buy") relative to the unrelated conditions (e.g., büpfe-kaufe, "jumpbuy"), separately for all three levels of verb regularity. These participle effects are modulated by regularity, that is, they are strongest for "regular" participles, weaker for "irregular 1" participles, and weakest for "irregular 2" participles. This is corroborated by the statistical analysis that revealed a significant interaction between relatedness, regularity, and electrodes from 390 to $480 \mathrm{msec}$ after target onset, indicating a graded, that is, successive reduction in the EEG signal regarding both amplitude and topography. Although "regular" verbs show widespread frontal, parietal, and temporal effects, these are reduced in amplitude and topography to frontal and temporal effects for "irregular 1" verbs and to a hardly visible effect for "irregular 2" verbs. Correspondingly, post hoc tests of the interaction revealed significant effects at frontal (F3, F4, Fz) and all central, temporal, parietal, and occipital electrode sites for "regular" verbs; at frontal electrodes (F3, F7, Fz)

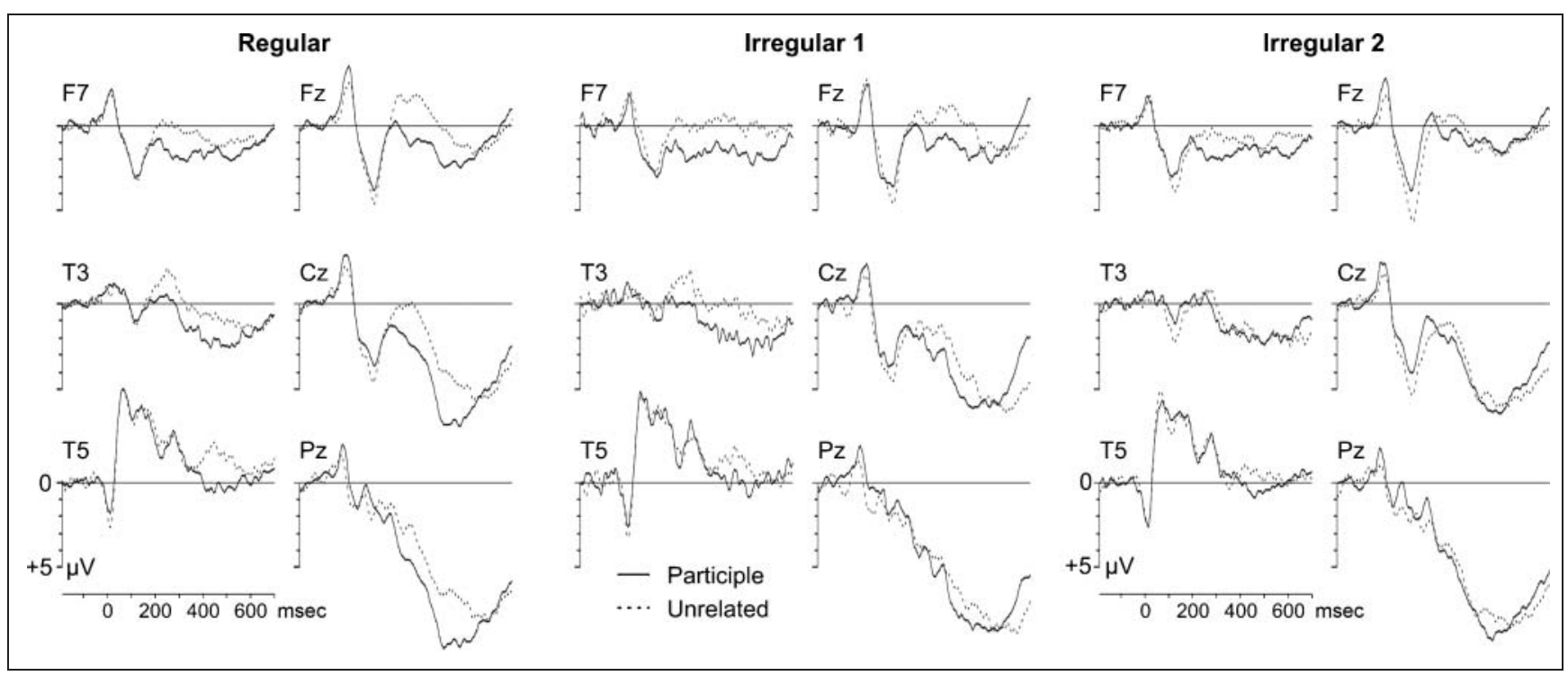

Figure 2. Grand-averaged ERPs of regular, semi-irregular, and irregular verb targets preceded by their participle or an unrelated verb. In this and the following figures, negativity is plotted upwards. 
as well as at $\mathrm{C} 3, \mathrm{~T} 3$, and $\mathrm{T} 5$ for "irregular 1" verbs; and only at T5 for "irregular 2" verbs.

Note that such a graded morphological priming effect would most probably remain undetected with a less finegrained analysis as it has been conducted in previous repetition-priming studies where the analysis focused on the time window in which the ERP modulations are generally largest and was limited to two levels of regularity. For example, in Münte et al. (1999), in the time window between 250 and $400 \mathrm{msec}$, regular verbs showed a morphological N400 priming effect, whereas irregular verbs showed no effect. To relate our finding of a graded effect to those results, we conducted a post hoc analysis in which we computed an ANOVA with factors Relatedness (participle/unrelated), Regularity ("regular"/"irregular 2"), and Electrode (19) for the time window from 200 to $550 \mathrm{msec}$, in which the ERP modulations are generally largest (cf. Figure 2). This analysis revealed a main effect of Relatedness and a marginally significant interaction of Relatedness and Regularity but no interactions with factor Electrode (see Table 4). Post hoc $t$ tests showed that the interaction resulted from a significant participle priming effect for regular verbs, $F(14)=27.40, p<.001$, that was absent for irregular verbs, $F(14)=1.88, p=.192$. We thus replicated the all-or-none results of Münte et al. (1999), that is, an N400 effect by regular participles alongside no effect by irregular participles. This supports our claim that a more fine-grained analysis and an intermediate semi-irregular condition are necessary to study whether morphological priming gradually varies with verb regularity.

\section{Is Participle Priming Full or Partial?}

To examine whether regular and irregular participles produce full or partial priming, we conducted an ANOVA with factors Relatedness (participle/identity), Regularity, and Electrodes. This analysis revealed a main effect of Relatedness from 360 to $480 \mathrm{msec}$ and a corresponding interaction between Relatedness and Electrodes from 360 to $690 \mathrm{msec}$ but no effects of Verb Regularity. That is, participle priming was partial for all verb types: It was more negative than identity priming, as indicated by post hoc tests, in a broad distribution including F4; Fz; and all central, parietal, and occipital electrodes (see Figure 3). Again, the interaction from 570 to $690 \mathrm{msec}$ indicated the reverse effect and is probably caused by an N400 latency difference. This effect was significant at F7, F8, Fp1, and Fp2.

\section{Is Semantic Priming Different for Regular and Irregular Verbs?}

Semantic priming was measured by comparing the influence of unrelated, semantically related, and identical primes on a verb target, assuming that the former will denote the least meaning relatedness and the latter will denote the strongest possible relatedness. Figure 4 shows the grand averages of unrelated, semantically related, and

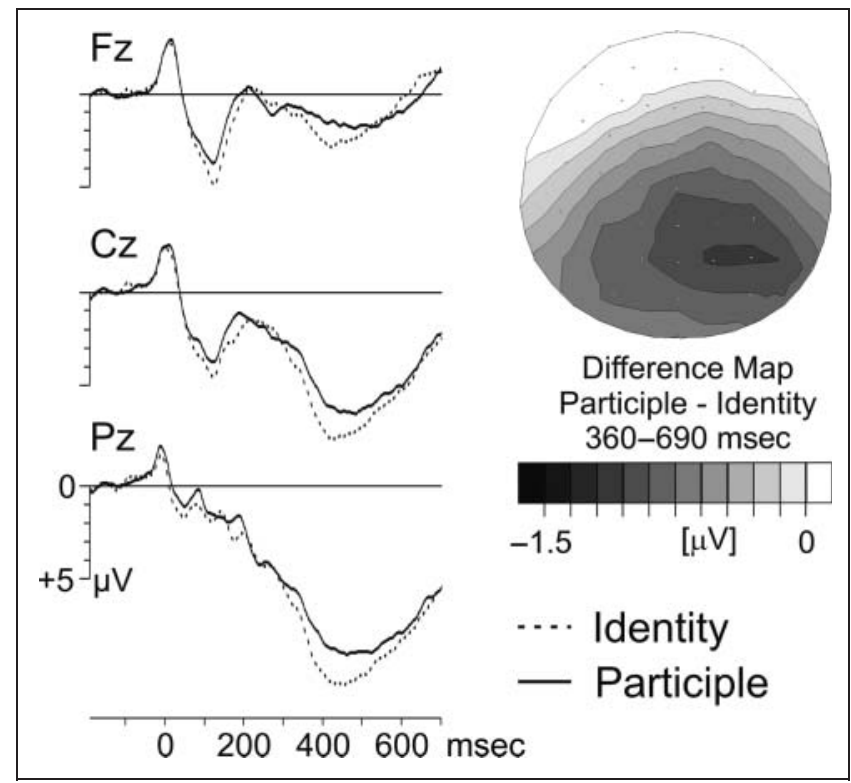

Figure 3. Grand-averaged ERPs of verb targets primed by themselves (identity) or by their participle, and corresponding topographic map of voltage differences

identical verb pairs, separately for all three levels of verb regularity. For all three levels of regularity, the curves start to diverge at about 200 msec after stimulus onset, with unrelated targets being most negative, semantically related targets being less negative, and identical targets being least negative. The maximal difference is reached between 400 and $500 \mathrm{msec}$, indicating a modulation of the N400 component by the type of meaning relatedness. Accordingly, an ANOVA with factors Relatedness (identity/semantic/ unrelated), Regularity, and Electrodes yielded a significant main effect of Relatedness for time intervals of 240-510 msec and a significant interaction between Relatedness and Electrodes for time intervals of 300-540 msec. There was no significant interaction with regularity. To investigate whether semantic priming is significant, post hoc $t$ tests compared the ERPs evoked by semantically related (e.g., zable-kaufe, "pay-buy") and unrelated (e.g., hüpfe-kaufe, "jump-buy") verb pairs for each electrode, yielding a broadly distributed N400 effect with a maximum at central and parietal electrodes and more negative potentials for unrelated targets at F3, F4, Fz, F7, C3, C4, Cz, P3, P4, Pz, O1, O2, T3, T5, and $\mathrm{T} 6$.

\section{Is Participle Priming Different from Semantic Priming?}

Finally, we investigated whether participle priming differs from semantic priming. For this purpose, we calculated the interaction $(\mathrm{P}-\mathrm{I}) \times(\mathrm{SP}-\mathrm{S})$, which tests for differences between the morphological $(\mathrm{P}-\mathrm{I})$ and semantic (SP-S) priming effects. The logic behind the comparison of $(\mathrm{P}-\mathrm{I})$ versus (SP-S) is that both comparisons vary in meaning relatedness between prime and target but represent the same inflectional difference (in conditions $\mathrm{P}$ and SP, the 
Figure 4. Grand-averaged ERPs of verb targets preceded by themselves (identity), a semantically associated, or an unrelated verb, separately for all three levels of verb regularity.

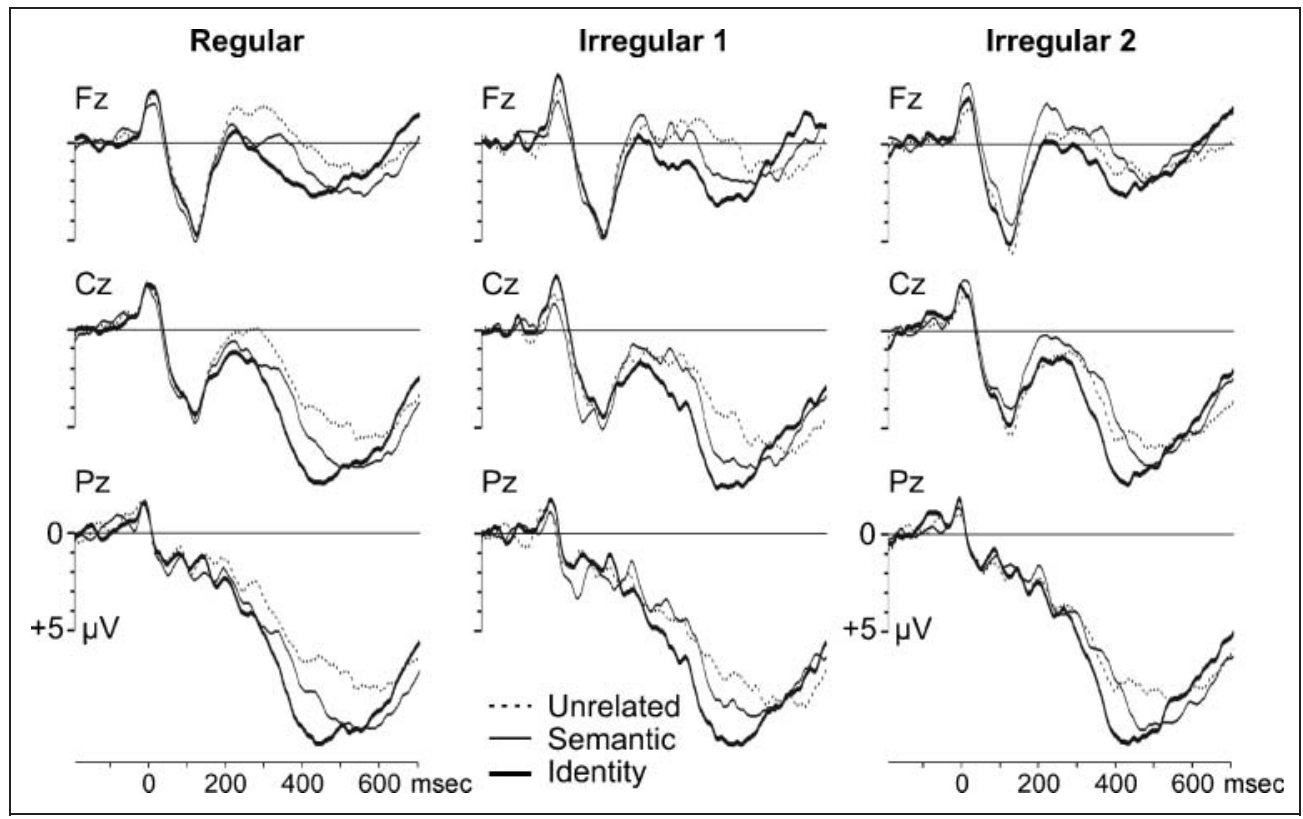

prime is in the participle and the target in the first/second person inflection; in conditions I and S, both the primes and the targets are in the first/second person inflection). That is, both differences denote the influence of the participle inflection, once when prime and target share their meaning $(\mathrm{P}-\mathrm{I})$ and once when prime and target are semantically related (SP-S). The differences (P-I) and (SP-S) were submitted to an ANOVA with factors Relatedness (morphological/semantic), Regularity, and Electrodes. This analysis revealed no effect of Regularity but an interaction between Relatedness and Electrodes for time intervals of 330-390 msec. Within this time window, post hoc $t$ tests revealed that the morphological and semantic effects differ significantly at central $(\mathrm{C} 4, \mathrm{Cz})$ and parietal $(\mathrm{P} 4, \mathrm{Pz})$ electrodes (see Figure 5A).

We conducted another post hoc analysis that calculated the difference between participle priming and semantic priming when measured relative to the unrelated con- dition. To this end, the differences (P-U) and (SP-U) were submitted to an ANOVA with factors Relatedness (morphological/semantic), Regularity, and Electrodes. This analysis revealed no effect of Regularity but a main effect of Relatedness for time intervals of 360-420 msec, indicating a broadly distributed stronger N400 effect for morphological compared with semantic priming with a maximum at left parietal electrodes (see Figure 5B).

\section{Behavioral Results}

One verb was excluded from the analyses because of incorrect coding. The data of one participant whose error rates (17\%) exceeded 3 SDs of the overall error mean (3.5\%) were removed. Means over word and nonword responses were calculated separately, and RTs exceeding 2.5 SDs from a participant's mean were excluded. The same analyses conducted on the EEG data were conducted on the RT data.
Figure 5. Grand-averaged ERPs and corresponding topographic maps of voltage differences between participle and semantic priming, calculated as differences (P-I) and (SP-S), respectively, in Figure $5 \mathrm{~A}$ and relative to an unrelated condition ( $\mathrm{P}-\mathrm{U}$ ) and (SP-U) in Figure $5 \mathrm{~B}$.

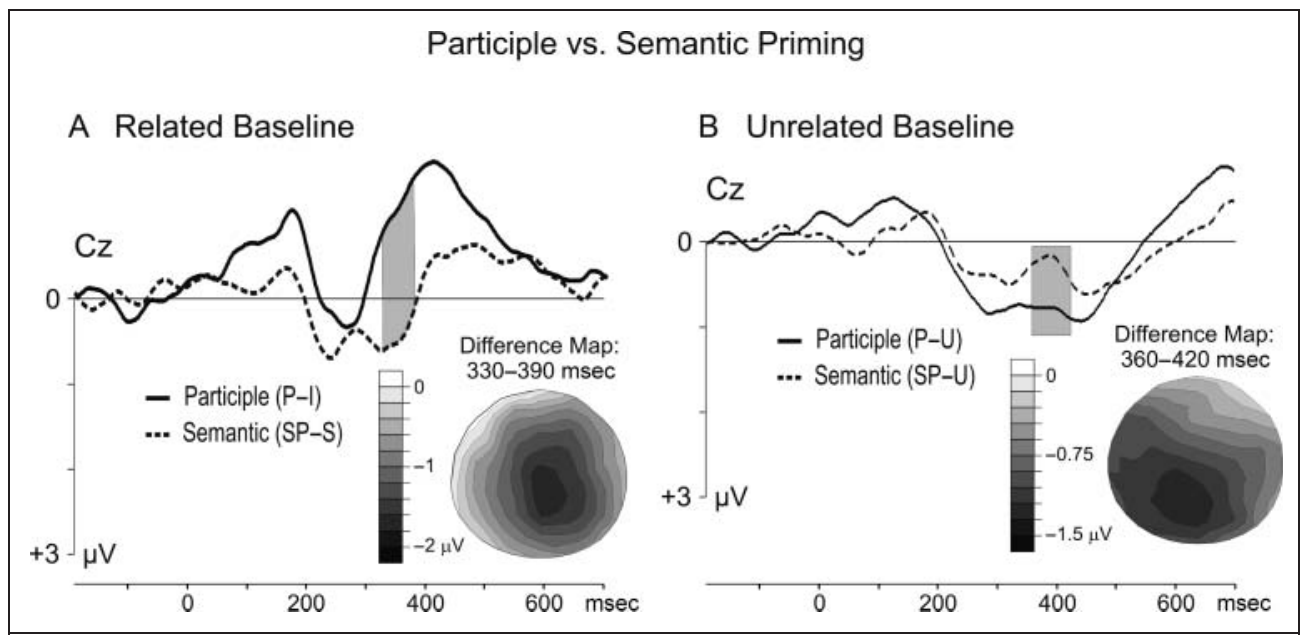




\section{Is Participle Priming Different for Regular and Irregular Verbs?}

In an ANOVA with factors Relatedness $(\mathrm{P} / \mathrm{U})$ and Regularity, both main effects and the interaction were significant (Relatedness: $F(1,19)=27.34, p<.0001$; Regularity: $F(2$, $38)=4.38, p=.0193$; Relatedness $\times$ Regularity: $F(2,38)=$ $4.07, p=.0250$ ). Importantly, the interaction indicated that inflected verb targets were responded to equally fast when they were preceded by participle primes ("regular": 623 msec, "irregular 1": $627 \mathrm{msec}$, "irregular 2": $621 \mathrm{msec}$ ) but not when they were preceded by unrelated primes ("regular": 662 msec, "irregular 1": 642 msec, "irregular 2": 635 msec; see Table 5).

\section{Is Participle Priming Full or Partial?}

In an ANOVA with factors Relatedness (I/P) and Regularity, only the main effect of Relatedness was significant, $F(1$, $19)=35.56, p<.0001$, indicating that the priming induced by participles was weaker than that by identical primes. The lack of an interaction suggested that this was true for all three verb types: The difference between the participle and identity conditions was 20 msec for "regular" verbs, $40 \mathrm{msec}$ for "irregular 1," and $25 \mathrm{msec}$ for "irregular 2" verbs. Hence, all verb types produced partial participle priming.

\section{Is Semantic Priming Different for Regular and Irregular Verbs?}

The nonsignificant interaction in the two-way ANOVA with factors Relatedness (I/S/U) and Regularity suggested that semantic priming did not vary with verb type.

\section{Is Participle Priming Different from Semantic Priming?}

As in the EEG experiment, the difference scores (P-I) and (SP-S) were submitted to a two-way ANOVA with factors Relatedness (morphological/semantic) and Regularity. Factor Relatedness was significant, $F(1,19)=10.73$, $p=.0040$, indicating that $(\mathrm{P}-\mathrm{I})$ indeed differs from (SP-S). Both effects were significantly different from zero (P-I: 29 msec, $t(59)=6.92, p<.0001$; SP-S: 10 msec, $t(59)=$ $2.80, p=.0068)$. Most importantly, as with the EEG data, the interaction with Regularity was not significant, suggesting that participle priming (P-I) differs from semantic priming (SP-S) for all verb types.

\section{DISCUSSION}

This study investigated whether linguistic verb categorieslabeled regular and irregular-are processed in a categorical or continuous way. To our knowledge, this is the first repetition-priming study in German that tested three verb regularities to indicate graded processing. Furthermore, this study analyzed more electrodes (not electrode clusters) and smaller time windows than previous studies. These analyses yielded graded effects between completely regular, semi-irregular, and completely irregular verbs that contradict a simple all-or-none classification. The purpose of this study was to systematically put to test the following predictions derived from the claim of the dual-mechanism account that regularly and irregularly inflected verb forms are stored in and processed by distinct systems.

\section{Is Participle Priming Different for Regular and Irregular Verbs?}

In contrast to the all-or-none assumptions of a dualmechanism account, the present data suggest that verb regularity is a continuous phenomenon. Our electrophysiological data have shown a graded participle priming effect relative to the unrelated condition: the strongest effect by completely regular participles, an intermediate effect by semi-irregular participles, and a minimal effect by completely irregular participles (see Figure 2). That is, the three verb types produced the same basic effect, which is modulated by the amplitude and by the number of affected electrodes. "Regular" participles showed a broadly distributed effect (with more negative curves for unrelated than for participle primes), extending from frontal, central, temporal, and parietal to occipital electrodes; the effect is reduced to frontal, central, and left temporal electrodes for "irregular 1" participles and diminished to a single left temporal electrode for "irregular 2" participles. Such graded effects indicate continuous processing, which, in turn, is best integrated in a single system.

In contrast to the differentiation between grammatical processing (LAN, P600) for regular verbs and semantic processing (N400) for irregular verbs, as hypothesized by a dual-mechanism account, this graded effect rather reflects an N400 modulation, as we would expect in accordance with semantic networks. As we have stated earlier, this would fit the assumptions that (a) repetition priming is usually reflected in N400 effects and (b) German participles are accessed for their stems, which differ in stem connectivity and thus yield different (graded) N400 modulations (for a detailed description of the model, see below).

Given that this study is the first to test subgroups of irregular verbs in German, we cannot refer to other studies for a direct comparison. However, our results are similar to the findings of a recent repetition-priming study in English (Kielar \& Joanisse, 2009) that found the strongest effects for regular English verbs, intermediate effects for suffixed irregular verbs, and the weakest effects for vowel-change irregular verbs. Another study observed graded ERP effects (Justus et al., 2008), although opposite from ours, with vowel-change irregular verbs producing the strongest priming. Graded priming effects have been repeatedly observed in behavioral studies as well. For example, irregular past tense forms with nested stems (shown-show) more strongly facilitated their base than irregular forms with stem changes (bought-buy; Feldman, 
Kostić, Basnight-Brown, Đurđević, \& Pastizzo, 2010; Basnight-Brown, Chen, Hua, Kostiç, \& Feldman, 2007).

One could argue that graded priming effects reflect the effects of orthographic rather than morphological similarity, because letter overlap between past tense/participle primes and their respective targets varies with verb regularity: Regular past tense/participles share most letters with the target, semi-irregular participles share less, and vowel-change irregular participles share least letters with the target. Indeed, also in our study, after stripping off the ge- prefix, "regular" participles shared most letters with their targets, "irregular 1" participles shared fewer, and "irregular 2" participles shared fewest letters with the targets. However, the ERP literature shows that sublexical processing such as the mapping of prelexical orthographic representations onto whole-word orthographic representations is most often reflected in early modulations of the N250 effect, whereas N400 modulations are assumed to reflect the mapping of whole-word representations onto meaning as well as lexical effects (e.g., Massol, Grainger, Dufau, \& Holcomb, 2010; Barber \& Kutas, 2007; Holcomb \& Grainger, 2007). The fact that all of the above-reviewed repetition-priming studies on regular and irregular inflection yielded N400 and late N400 modulations (see Table 1) indicates that the priming effects by regular and irregular participles result from lexical processing rather than orthographic priming.

At first glance, graded effects seem to contrast with previous repetition-priming studies in German, English, and Spanish (Rodriguez-Fornells et al., 2002; Münte et al., 1999; Weyerts et al., 1996) that were interpreted in terms of all-or-none effects between regular and irregular verbs. However, as we have summarized above, a closer look reveals a more subtle picture: In these studies, regular participles showed a reduction in the N400 and post-N400 range as well as a late right-frontal positivity; irregular participles, too, showed a reduction in the N400 and a late right centroparietal positivity. Had we (a) considered only two types of regularity and (b) the midline electrodes of our data, (c) used coarse-grained time intervals (averaging over 200-300 $\mathrm{msec}$ ), and (d) reduced the analyses to few electrodes or electrode clusters, our data would confirm an all-or-none difference between completely regular and completely irregular verbs (see Figure 2). Indeed, by means of our post hoc analysis, we were able to replicate the interaction between regularity and priming, as it is hypothesized by dual-mechanism accounts: Averaging over a time window between 200 and 550 msec, regular participles induced an N400 effect that was absent for irregular verbs. We thus argue that fine-grained analyses are crucial to test categorical versus continuous differences.

\section{Is Participle Priming Full or Partial?}

A categorical processing distinction between regular and irregular verbs should yield different priming patterns for these verb types, which we did not find: Regularity did not interact with effects induced by identical and participle primes. Rather, results showed partial priming effects (i.e., participle priming less than identity priming) for both regular and irregular verbs. In the RT analyses, participles induced slower responses than identical primes. In the ERP analysis, targets showed more negative potentials when preceded by participles than when preceded by identical primes between 360 and 570 msec at central, parietal, and occipital sites, which correspond to a broadly distributed N400 effect (see Figure 3).

At first glance, our partial priming effects for "regular" participles seem to contradict previous findings in German that reported full priming, in both behavioral (Sonnenstuhl et al., 1999) and ERP (Weyerts et al., 1996) data. However, as we have previously shown (Smolka et al., 2007), the findings of partial priming by "irregular 1" participles in the behavioral study may have been a confound of frequency. Furthermore, recent behavioral findings (Smolka, Zwitserlood, Wiese, Marslen-Wilson, \& Rösler, under revision) have revealed that whether regular participles induce full or partial priming depends on their frequency and not, as suggested by a dual-mechanism account, on a rule-based processing system per se.

Furthermore, unlike in our study, the only previous ERP study in German (Weyerts et al., 1996) used participles as targets that were primed either by themselves (identity), by an infinitive, or by an unrelated verb. It is possible that the priming of inflections is not symmetrical (e.g., Schriefers, Friederici, \& Graetz, 1992) and thus caused the different results. Importantly, our study also found partial priming effects for irregular verbs, which contrasts with other repetition-priming studies that did not find any effects at all for irregular verbs (Rodriguez-Fornells et al., 2002; Münte et al., 1999). Furthermore, because these latter two studies did not make use of identity priming, they were not able to distinguish between full and partial priming effects.

If both regular and irregular verbs may produce full and partial priming effects, should we still infer, as suggested by a dual-mechanism account, that full priming indicates stem access whereas partial priming indicates whole-word storage? We rather prefer to conclude that full and partial priming patterns must not necessarily be taken to indicate a particular storage mechanism. Rather, experimental approaches other than full or partial priming should be used to assess whether stem access occurs.

For example, we have used nonword priming to show that irregular participles are accessed via their stems (for RT data: Smolka et al., 2007; for ERP data: Smolka, Pöhnl, \& Eulitz, 2012). Nonwords that comprised illegal combinations of (regular or irregular) stems and (regular or irregular) suffixes primed their corresponding base verbs to the same extent as correct participles did (*gewurftwerfen vs. geworfen-werfen, "*threwed-throw vs. thrown-throw"). With respect to ERPs, nonwords induced more positive waveforms relative to the unprimed condition (N400 effects) that did not differ from the N400 effects induced by correct participles. Because nonwords do not 
exist and thus cannot be stored in lexical memory, their stems must have been accessed to produce priming on the base verbs. Equivalent nonword priming to regular and irregular verbs thus contradict the notion of a dualmechanism account that irregular stems are not accessible (Clahsen et al., 2002) and rather indicate that both regular and irregular stems are stored and processed within the same system.

\section{Are Semantic Priming Effects Different for Regular and Irregular Verbs?}

Several studies have indicated that English regular and irregular verbs differ with respect to their semantic richness and semantic interconnections with other words (e.g., Baayen \& Moscoso del Prado Martin, 2005). In this study, we tested the priming effects between semantically related verb pairs. The ERP data revealed strong semantic association effects, namely broadly distributed N400 effects in the time intervals between 240 and $510 \mathrm{msec}$ that reflect the relatedness between prime-target pairs: strongest negativity for unrelated verbs, less negativity for semantically related verbs, and weakest negativity for identical verbs. Most importantly, all verb types showed strong semantic priming on the N400, both when comparing semantically related to unrelated and to identical prime-target pairs (see Figure 4).

Strong semantic priming effects of verbs in terms of N400 modulations, in contrast to unstable effects in the RT data, have been previously documented in German (e.g., Rösler et al., 2001). However, we are not aware of a previous study that tested whether regular and irregular verbs differ with regard to semantic priming effects.

\section{Is Participle Priming Different from Semantic Priming?}

This question concerns the storage and processing of irregular participles. A dual-mechanism account holds that every irregularly inflected verb form has a separate lexical and semantic representation, similar to semantically associated words. If the priming of irregular participles occurs in associative memory, we should see effects similar to those of semantic associates, that is, we should find N400 deflections for participle priming that resemble those of semantic priming.

To directly compare morphological and semantic effects to the same verb target, we used verbs as primes in both morphological and semantic conditions. We tested whether participle priming differs from semantic priming by examining the interaction $(\mathrm{P}-\mathrm{I}) \times(\mathrm{SP}-\mathrm{S})$. This interaction tests the hypothesis that participle and semantic priming are equal. For both RTs and ERPs, the interaction was significant, confirming a qualitative difference between participle and semantic priming. In addition, the post hoc analysis $(\mathrm{P}-\mathrm{U}) \times(\mathrm{SP}-\mathrm{U})$ confirmed these results (see Figure $5 \mathrm{~A}$ and $\mathrm{B}$ ). However, neither the behavioral nor the electrophysiological data showed an interaction with regularity. That is, participle priming differs from semantic priming for regular as well as for irregular verbs.

These findings go against the assumption of a dualmechanism account that irregularly inflected forms are connected in a semantic network whereas regularly inflected verbs are not. For example, Stanners et al. (1979) interpreted their behavioral data of partial priming for both irregularly inflected verbs and semantically related pairs to indicate that irregular verbs relate to each other in similar ways as do semantic associates such as black and white or swan and goose.

However, our findings fit those of previous ERP studies that compared the priming of verb inflection with that of semantic noun associates. For example, Marslen-Wilson and Tyler (1998) found that regular and irregular past tense priming showed LAN together with N400 modulations, whereas semantically associated word pairs like cello violin showed an N400 effect only. The LAN was taken as evidence that past tense forms induce morphological priming in contrast to pure semantic priming. The authors concluded that "the underlying relationship between an irregular past tense and its stem is more similar to the morphological relationship between a regular inflected form and its stem than to the relationship between pairs that are just semantically related" (p. 433). Also, Kielar and Joanisse (2009) found smaller N400 effects by semantic associates than by any of the verb types and concluded that "the morphological priming effects cannot be attributed to formal or semantic similarity alone" (p. 1387).

To summarize, we found substantial behavioral and ERP evidence for the claim that regular and irregular forms are processed similarly, supporting the idea of a single system: (1) graded effects of participle priming between completely regular ("regular"), semi-irregular ("irregular 1"), and completely irregular ("irregular 2") participles; (2) no interaction between regularity and (full or partial) priming patterns, that is, partial priming for all verb regularities; and (3) participle priming that differed from semantic priming for both regular and irregular verbs. Most importantly, both the ERP and the behavioral data revealed graded differences between the verb regularities. This general convergence means that the participle priming mechanism involves a general cognitive phenomenon that can be captured by different methods. We have shown that the obvious linguistic distinction between regular and irregular word forms does not have a one-to-one mapping onto either storage or processing principles rendering our results even more robust and credible. Our data are thus best accommodated in a single-system model that allows for the interplay of diverse factors as outlined below.

\section{Model of Lexical Representation in German}

The present model is based on the stem-based framework for verb inflections and derivations suggested by Smolka and colleagues (Smolka, Preller, et al., under revision; 
Smolka et al., 2007, 2009; Smolka, 2005). Its main feature is that complex verbs, including regularly and irregularly inflected verbs as well as semantically transparent and opaque derivations, are decomposed into stem and affixes and are lexically represented via their stems (and affixes).

The model comprises a form level, an intermediate level with lexical representations, and a conceptual level. At the form level, form-to-meaning mappings occur for both auditorily and visually presented stimuli. Because morphemes are the smallest meaningful units, they emerge as the product of form-to-meaning mappings. We refer to other studies for a detailed description of the nature of these early mappings (cf. Crepaldi, Rastle, Coltheart, \& Nickels, 2010; Marslen-Wilson, Bozic, \& Randall, 2008; Diependaele, Sandra, \& Grainger, 2005). That is, with respect to inflections, regular participles like gezäbmt ("tamed") and irregular participles like geworfen ("thrown") are segmented into their constituent components regardless of verb regularity: the former into the prefix ge-, the stem $z \ddot{a} b m$, and the suffix $-t$; and the latter into ge-, worf, and -en. These constituents activate their stem representations at the lexical level. That is, an irregularly inflected participle like geworfen is not only segmented into its stem and affixes at the (prelexical) form level but is also lexically represented via its stem \{worf and affixes $\{$ ge- $\}$ and $\{$-en $\}$.

Following decomposition, these lexical entries of the stem and affixes directly activate their corresponding concepts at the conceptual level. Hence, the stem worf will activate the meaning "throw," and the affixes ge- and -en will indicate "past" in form of the participle formation. This activation facilitates the recognition of the target werfe ("I throw") that is decomposed into werf and -e and whose lexical representations $\{$ werf $\}$ and $\{$-e $\}$ activate the same concept "throw" at the conceptual level together with the concepts for "I" and "present tense." This accounts for the findings of this study that the activation of participles induces priming to other morphologically related verbs. Furthermore, it explains why (in our study) regular participle priming (gekauft-kaufe) was partial, that is, less than identity priming (kaufe-kaufe): Both the participle and the target are lexically represented via the stem $\{$ kauf $\}$ and activate the same concept "buy"; nevertheless, the participle affixes $\{g e-\}\{$ en $\}$ activate different concepts from those of the first verb inflection of the target $\{-\mathrm{e}\}$.

In our stem-based account, graded effects of participle priming may be accounted for by the fact that the participle stems of regular and irregular verbs possess different type and token frequencies and thus different connectivity with other inflectional forms. Regular stems occur, by definition, not only in the participle but in the whole verb paradigm, such as the infinitive, present tense, past tense, conditional, and imperative. Regular verbs thus have only one stem type, which is highly connected with other inflectional forms. The stems of "irregular 1" participles will hold an intermediate position, because they occur both in the participle and in the infinitive and possibly in other verb forms as well, whereas the stems of "irregular 2" participles will be fewest and least interconnected within the verbal paradigm, because "irregular 2" verbs comprise many different stem types. Hence, if all participles are parsed and accessed for their stem, regular participles will activate not only the lexical representation of the participle stem but also that of all other inflectional forms carrying the same stem, whereas irregular participles will induce less activation because their stems will coactivate fewer inflectional forms. Whether the mechanism we see here in form of a left-lateralized $\mathrm{N} 400$ is an indication of stem access and stem connectivity remains to be tested in future experiments. In particular, such experiments will need to manipulate the type and token frequencies of words, stems, and inflectional forms carrying the same stem as independent factors. In any case, we believe that this assumption may provide a better reflection of the graded brain responses than the allor-none assumptions drawn by dual-mechanism accounts.

There are further models that may account for the present findings, because they assume similar processing for regular and irregular verb inflection. For example, in distributed morphology, both regularly and irregularly inflected verbs are processed within a single system (e.g., Stockall \& Marantz, 2006; Embick \& Marantz, 2005). This model resembles ours by assuming that both regular and irregular verb forms are decomposed into stems and affixes followed by root-based lexical access. However, it differs from our model (and resembles dual-mechanism accounts) by assuming that lists must be referred to for the irregular verbs but not for the regular verbs and that a blocking principle prevents the regular suffix to be applied to irregular forms. Different from dual-mechanism accounts is their assumption that irregular forms are not stored as unanalyzed wholes. Rather, the lists of irregular verbs are organized according to phonological similarities, describing both the phonological realization of the stem and the choice of irregular suffix $(\varnothing$ and $-t)$. We interpret the model in such a way that graded effects of participle priming (as we observe in this study) could possibly be explained by different resting levels of the roots that are activated on past tense access.

Also, the dual-system model of Marslen-Wilson and Tyler (2007) allows German regular and irregular participles to be processed in qualitatively the same way, because both types are decomposable into stems plus inflectional affixes. These inflectional affixes should obligatorily engage the same left-hemispheric system that supports the analysis of morpho-phonologically complex inflected forms. Given that both regular and irregular inflections in German occur with overt affixes (besides some imperatives that do not take overt affixes in any of the verb regularities), regular and irregular verb inflection in German must be incorporated in a system that processes both stems and affixes, regardless of regularity. However, we are not sure what details will be given for graded effects of verb regularity in that model. 
Altogether, we may conclude that the present data of German verb inflection are best accommodated in a single system. Different from other models, our stembased account has some additional features that allow us to explain our recent nonword data (Smolka et al., 2012): Stems are clustered according to their morphological relatedness and not according to syntactic category. This feature is derived from the fact that the same stem may occur in the verbal, adjectival, and/or noun paradigm. For example, the stem of the regular verb zäbmen ("tame," verb) occurs not only in verbal forms like zäbme ("I tame") but also in deverbal nouns like Zäbmung ("taming"); and the stem Zabm occurs in the adjective zabm ("tame," adjective) and in the deadjectival noun zabmbeit ("tameness"). Hence, the lexical representations of the stem allomorphs zäbm and zabm ("tame," adjective) are clustered and will activate the same concept "tame" at the conceptual level; and the stem allomorphs werf, wirf, warf, worf, würf ("throw," noun) and wurf ("throw," noun) are clustered and will activate the same concept "throw." This assumption explains our previous behavioral and ERP findings that nonwords like *gezabmt or *gewurft (consisting of adjectival/noun stems and participle affixes) facilitate the base verbs zäbmen and werfen, respectively, as robustly as the correct participles gezäbmt and geworfen do (Smolka et al., 2012; Smolka et al., 2007).

By contrast, it is not clear, how either distributed morphology or the dual-system model (Marslen-Wilson \& Tyler, 2007) can account for these nonword priming effects in German. In distributed morphology, for example, suffixes and stem realizations are fully specified in the irregular lists so that the system will not be able to access any form that is not listed, as will be the case with nonwords of the type *gewurft, nor will the system be able to recognize the nonword *gezabmt, because the correct regular participle gezäbmt ("tamed") is constructed via rule, which will neither produce nor recognize a nonstandardized/ unlisted form. We thus prefer our stem-based account over the other cited ones to explain our previous and present findings on verb inflections in German.

To summarize, our data fit best in a single-system model (Smolka, Preller, et al., under revision; Smolka et al., 2012; Smolka et al., 2007, 2009) that allows for stem access in both inflections and derivations, regardless of regularity and semantic transparency. The number of stem allomorphs and their connectivity to different inflectional forms will affect both lexical access and activation effects within the lexical network.

\section{Acknowledgments}

This study was supported by the German Research Foundation (DFG) Grant FOR 254/2 to Richard Wiese and Frank Rösler.

Reprint requests should be sent to Eva Smolka, Department of Linguistics, University of Konstanz, 78457 Konstanz, Germany, orvia e-mail: eva.smolka@uni-konstanz.de.

\section{Notes}

1. All verbs were complex verbs, with different particles or prefixes attached to the same stem, such as aufladen (load on) and abladen (load off), so as to increase the number of irregular verbs.

2. In Sonnenstuhl et al. (1999), "regular" identity primes (and targets) had a mean surface frequency of 3.76, a participle frequency of 19.9, and a lemma frequency of 110 per million; whereas "irregular 1" identity primes (and targets) had a mean surface frequency of 9.62, a participle frequency of 32.6, and a mean lemma frequency of 291 per one million (CELEX database; Baayen et al., 1993). A paired $t$ test confirmed that the difference between the "regular" and "irregular 1" identity condition was significant, $p<.05$.

3. Clahsen et al. (2002) assume that German participles with the regular $-t$ suffix are parsed, whereas "irregular 1 " and "irregular 2" participles that do not take the "regular" - $t$ suffix must be retrieved as whole-word units.

4. ERP studies require a critical amount of stimuli per condition (around 25, the more the better). However, there are no more than 22 "irregular 1" verbs that can be matched on frequency with both "regular" and "irregular 2" verbs (see also Table 2), so that we could not take larger samples of these verbs. To conduct an experiment with both within-subject and within-target design, we preferred target repetition over the use of five different lists, as it is usually done in behavioral experiments. To this end, each participant saw each target with five different primes. The different prime conditions of the same target were evenly allocated to blocks by means of Latin Square, so that any effect of target repetition was equally balanced across conditions. Furthermore, in the EEG, effects of target repetition have been shown to disappear after 19 intervening items or $20 \mathrm{~min}$ (Rugg, 1990). Given that, in our experiment, each block comprised 264 prime-target pairs (i.e., 528 items) and took about 20 min with breaks in-between blocks, we may assume that target repetition was not effective in our study.

5. Note that a single ANOVA including all prime types and verb regularities - as it could be done with RT data-would result in a 5 (prime type) $\times 3$ (regularity) $\times 19$ (electrodes) ANOVA $\times 30$ time windows in the EEG analysis because of the additional factors of electrodes and time windows. Such an analysis is too complex and thus needs to be split into separate analyses.

\section{REFERENCES}

Allen, M., Badecker, W., \& Osterhout, L. (2003). Morphological analysis in sentence processing: An ERP study. Language and Cognitive Processes, 18, 405-430.

Bayyen, R. H., \& Moscoso del Prado Martin, F. (2005). Semantic density and past-tense fomation in three Germanic languages. Language, 81, 666-698.

Baayen, R., Piepenbrock, R., \& Van Rijn, H. (1993). The CELEX lexical database [CD-ROM]. Philadelphia, PA: Linguistic Data Consortium, University of Pennsylvania.

Barber, H. A., \& Kutas, M. (2007). Interplay between computational models and cognitive electrophysiology in visual word recognition. Brain Research Reviews, 53, 98-123.

Basnight-Brown, D. M., Chen, L., Hua, S., Kostiç, A., \& Feldman, L. B. (2007). Monolingual and bilingual recognition of regular and irregular English verbs: Does sensitivity to word form vary with language experience? Journal of Memory and Language, 57, 65-80.

Bentin, S., McCarthy, G., \& Wood, C. (1985). Event-related potentials, lexical decision, and semantic priming. 
Electroencephalography and Clinical Neurophysiology, 60, 343-355.

Bentin, S., \& Peled, B. (1990). The contribution of task-related factors to the ERP repetition effects at short and at long lags: Electrophysiological evidence. Memory \& Cognition, 18, 359-366.

Beretta, A., Campbell, C., Carr, T. H., Huang, J., Schmitt, L. M., Christianson, K., et al. (2003). An ER-fMRI investigation of morphological inflection in German reveals that the brain makes a distinction between regular and irregular forms. Brain and Language, 85, 67-92.

Bodner, G. E., \& Masson, M. E. J. (2003). Beyond spreading activation: An influence of relatedness proportion on masked semantic priming. Psychonomic Bulletin and Review, 10, 645-652.

Brunel, N., \& Lavigne, F. (2009). Semantic priming in a cortical network model. Journal of Cognitive Neuroscience, 21, 2300-2319.

Chomsky, N. (1970). Remarks on nominalization. In R. Jacobs \& P. Rosenbaum (Eds.), Readings in English transformational grammar (pp. 184-221). Waltham, MA: Ginn.

Clahsen, H. (1999). Lexical entries and rules of language: A multidisciplinary study of German inflection. Behavioral and Brain Sciences, 22, 991-1060.

Clahsen, H., Prüfert, P., Eisenbeiss, S., \& Cholin, J. (2002). Strong stems in the German mental lexicon: Evidence from child language acquisition and adult processing. In I. Kaufmann \& B. Stiebels (Eds.), More than words. A Festschrift for Dieter Wunderlich (pp. 91-112). Berlin: Akademie-Verlag.

Collins, A. M., \& Loftus, E. F. (1975). A spreading-activation theory of semantic processing. Psychological Review, 82, 407-428.

Crepaldi, D., Rastle, K., Coltheart, M., \& Nickels, N. (2010). "Fell" primes "fall," but does "bell" prime "ball"? Masked priming with irregularly inflected primes. Journal of Memory and Language, 63, 83-99.

Davis, M. H., Meunier, F., \& Marslen-Wilson, W. D. (2004). Neural responses to morphological, syntactic, and semantic properties of single words: An fMRI study. Brain and Language, 89, 439-449.

Dell, G. S. (1986). A spreading-activation theory of retrieval in sentence production. Psychological Review, 93, $283-321$.

Diependaele, K., Sandra, D., \& Grainger, J. (2005). Masked cross-modal morphological priming: Unravelling morphoorthographic and morpho-semantic influences in early word recognition. Language and Cognitive Processes, 20, 75-114.

Embick, D., \& Marantz, A. (2005). Cognitive neuroscience and the English past tense: Comments on the paper by Ullman et al. Brain and Language, 93, 243-247.

Feldman, L. B., Kostić, A., Basnight-Brown, D. M., Đurđević, D. F., \& Pastizzo, M. J. (2010). Morphological facilitation for regular and irregular verb formations in native and non-native speakers: Little evidence for two distinct mechanisms. Bilingualism: Language and Cognition, 13, 119-135.

Forster, K. I., Davis, C., Schoknecht, C., \& Carter, R. (1987). Masked priming with graphemically related forms: Repetition or partial activation? The Quarterly Joumal of Experimental Psychology, 39, 211-251.

Fowler, C. A., Napps, S. E., \& Feldman, L. (1985). Relations among regular and irregular morphologically related words in the lexicon as revealed by repetition priming. Memory and Cognition, 13, 241-255.

Gross, M., Say, T., Kleingers, M., Clahsen, H., \& Münte, T. F. (1998). Human brain potentials to violations in morphologically complex Italian words. Neuroscience Letters, 214, 83-86.

Hennighausen, E., Heil, M., \& Rösler, F. (1993). A correction method for DC drift artifacts. Electroencephalography and Clinical Neurophysiology, 86, 199-204.

Holcomb, P., \& Grainger, J. (2007). Exploring the temporal dynamics of visual word recognition in the masked repetition priming paradigm using event-related potentials. Brain Research, 1180, 39-58.

Huynh, H., \& Feldt, L. S. (1976). Estimation of the Box correction for degrees of freedom from sample data in randomized block and split-plot designs. Journal of Educational Statistics, 1, 69-82.

Jaeger, J. J., Lockwood, A. H., Kemmerer, D. L., Van-Valin, R. D., Murphy, B. W., \& Khalak, H. G. (1996). A positron emission tomographic study of regular and irregular verb morphology in English. Language, 72, 451-497.

Justus, T., Larsen, J., De Mornay Davies, P., \& Swick, D. (2008). Interpreting dissociations between regular and irregular past-tense morphology: Evidence from event-related potentials. Cognitive, Affective, \& Behavioral Neuroscience, 8, 178-194.

Khader, P., Scherag, A., Streb, J., \& Rösler, F. (2003). Differences between noun and verb processing in a minimal phrase context: A semantic priming study using event-related brain potentials. Cognitive Brain Research, 17, 293-313.

Kielar, A., \& Joanisse, M. F. (2009). Graded effects of regularity in language revealed by $\mathrm{N} 400$ indices of morphological priming. Journal of Cognitive Neuroscience, 22, 1373-1398.

Krott, A., Baayen, R., \& Hagoort, P. (2006). The nature of anterior negativities caused by misapplications of morphological rules. Journal of Cognitive Neuroscience, 18, 1616-1630.

Kutas, M., \& Federmeier, K. D. (2000). Electrophysiology reveals semantic memory use in language comprehension. Trends in Cognitive Sciences, 4, 463-470.

Kutas, M., \& Federmeier, K. D. (2007). Event-related brain potential (ERP) studies of sentence processing. In E. Gaskell (Ed.), The Oxford handbook of psycholinguistics (pp. 385-406). Oxford, UK: Oxford University Press.

Lavric, A., Pizzagalli, D., Forstmeier, S., \& Rippon, G. (2001). A double-dissociation of English past-tense production revealed by event-related potentials and low-resolution electromagnetic tomography (LORETA). Clinical Neurophysiology, 112, 1833-1849.

Marslen-Wilson, W. (1999). Abstractness and combination: The morphemic lexicon. In S. Garrod \& M. J. Pickering (Eds.), Language processing (pp. 101-119). Hove: Psychology Press.

Marslen-Wilson, W., Bozic, M., \& Randall, B. (2008). Early decomposition in visual word recognition: Dissociating morphology, form, and meaning. Language and Cognitive Processes, 23, 394-421.

Marslen-Wilson, W., \& Tyler, L. K. (1998). Rules, representations, and the English past tense. Trends in Cognitive Sciences, 2, 428-435.

Marslen-Wilson, W., \& Tyler, L. K. (2007). Morphology, language and the brain: The decompositional substrate for language comprehension. Philosophical Transactions of the Royal Society of London, Series B, Biological Sciences, 362, 823-836.

Massol, S., Grainger, J., Dufau, S., \& Holcomb, P. (2010). Masked priming from orthographic neighbors: An ERP investigation. Journal of Experimental Psychology: Human Perception and Performance, 36, 162-174.

Morris, J., \& Holcomb, P. J. (2005). Event-related potentials to violations of inflectional verb morphology in English. Cognitive Brain Research, 25, 963-981. 
Münte, T. F., Say, T., Clahsen, H., Schiltz, K., \& Kutas, M. (1999). Decomposition of morphologically complex words in English: Evidence from event-related brain potentials. Cognitive Brain Research, 7, 241-253.

Napps, S. E. (1989). Morphemic relationships in the lexicon: Are they distinct from semantic and formal relationships? Memory and Cognition, 17, 729-739.

Newman, A. J., Ullman, M. T., Pancheva, R., Waligura, D. L., \& Neville, H. J. (2007). An ERP study of regular and irregular English past tense inflection. Neuroimage, 34, 435-445.

Pastizzo, M., \& Feldman, L. B. (2002). Discrepancies between orthographic and unrelated baselines in masked priming undermine a decompositional account of morphological facilitation. Journal of Experimental Psychology: Learning, Memory, and Cognition, 28, 244-249.

Penke, M., Weyerts, H., Gross, M., Zander, E., Münte, T. F., \& Clahsen, H. (1997). How the brain processes complex words: An event-related potential study of German verb inflections. Cognitive Brain Research, 6, 37-52.

Pinker, S. (1998). Rules of language. In P. Thagard (Ed.), Mind readings: Introductory selections on cognitive science (pp. 77-92). Cambridge, MA: MIT Press.

Pinker, S., \& Ullman, M. T. (2002). The past and future of the past tense. Trends in Cognitive Sciences, 6, 456-463.

Prasada, S., \& Pinker, S. (1993). Generalization of regular and irregular morphological patterns. Language and Cognitive Processes, 8, 1-56.

Ramscar, M. (2002). The role of meaning in flection: Why the past tense does not require a rule. Cognitive Psychology, 45, 45-94.

Rodriguez-Fornells, A., Clahsen, H., Lleo, C., Zaake, W., \& Münte, T. F. (2001). Event-related brain responses to morphological violations in Catalan. Cognitive Brain Research, 11, 47-58.

Rodriguez-Fornells, A., Münte, T. F., \& Clahsen, H. (2002). Morphological priming in Spanish verb forms: An ERP repetition priming study. Journal of Cognitive Neuroscience, 14, 443-454.

Rösler, F., Friederici, A., Pütz, P., \& Hahne, A. (1993). Event related brain potentials while encountering semantic and syntactic constraint violations. Journal of Cognitive Neuroscience, 5, 345-362.

Rösler, F., Streb, J., \& Haan, H. (2001). Event-related brain potentials evoked by verbs and nouns in a primed lexical decision task. Psychophysiology, 38, 694-703.

Rugg, M. D. (1990). Event-related brain potentials dissociate repetition effects of high- and low-frequency words. Memory and Cognition, 18, 367-379.

Sach, M., Seitz, R. J., \& Indefrey, P. (2004). Unified inflectional processing of regular and irregular verbs: A PET study. NeuroReport, 15, 533-537.

Schriefers, H., Friederici, A., \& Graetz, P. (1992). Inflectional and derivational morphology in the mental lexicon:
Symmetries and asymmetries in repetition priming. The Quarterly Journal of Experimental Psychology, 44, 373-390.

Seidenberg, M. S., \& Arnoldussen, A. (2003). The brain makes a distinction between hard and easy stimuli: Comments on Beretta et al. Brain and Language, 85, 527-530.

Smolka, E. (2005). The basic ingredients of lexical access and representation: Evidence from German participles (Doctoral dissertation). Philipps University Marburg, Germany.

Smolka, E., Komlósi, S., \& Rösler, F. (2009). When semantics means less than morphology: Processing German prefixed verbs. Language and Cognitive Processes, 24, 337-375.

Smolka, E., Pöhnl, V., \& Eulitz, C. (2012). Electrophysiological evidence for stem access in regular and irregular German participles. Proceedings of the Nineteenth Annual Cognitive Neuroscience Society Meeting (CNS), Chicago, USA (p. 137).

Smolka, E., Preller, K., \& Eulitz, C. (under revision). "Understand" primes "stand": Morphological structure overrides semantic compositionality in the lexical representation of German complex verbs.

Smolka, E., Zwitserlood, P., \& Rösler, F. (2007). Stem access in regular and irregular inflection: Evidence from German participles. Journal of Memory and Language, 57, 325-347.

Smolka, E., Zwitserlood, P., Wiese, R., Marslen-Wilson, W., \& Rösler, F. (under revision). Priming effects of German participles-The past-tense debate is not over yet.

Sonnenstuhl, I., Eisenbeiss, S., \& Clahsen, H. (1999). Morphological priming in the German mental lexicon. Cognition, 72, 203-236.

Stanners, R. F., Neiser, J. J., Hernon, W. P., \& Hall, R. (1979). Memory representation for morphologically related words. Journal of Verbal Learning and Verbal Behavior, 18, 399-412.

Stockall, L., \& Marantz, A. (2006). A single route, full decomposition model of morphological complexity: MEG evidence. The Mental Lexicon, 1, 85-123.

Ullman, M. T., Corkin, S., Coppola, M., Hickok, G., Growdon, J. H., Koroshetz, W. J., et al. (1997). A neural dissociation within language: Evidence that the mental dictionary is part of declarative memory, and that grammatical rules are processed by the procedural system. Journal of Cognitive Neuroscience, 9, 266-276.

Ullman, M. T., Pancheva, R., Love, T., Yee, E., Swinney, D., \& Hickok, G. (2005). Neural correlates of lexicon and grammar: Evidence from the production, reading, and judgment of inflection in aphasia. Brain and Language, 93, 185-238.

Weyerts, H., Münte, T. F., Smid, G. O. M. H., \& Heinze, H.-J. (1996). Mental representations of morphologically complex words: An event-related potential study with adult humans. Neuroscience Letters, 206, 125-128.

Wiese, R. (1996). The phonology of German. New York: Oxford University Press. 